\title{
SEISMIC FRAGILITY OF SUSPENDED CEILING SYSTEMS USED IN NZ BASED ON COMPONENT TESTS
}

\author{
Rajesh P. Dhakal ${ }^{1}$, Gregory A. MacRae ${ }^{2}$, Atefeh Pourali ${ }^{3}$ and \\ Giacomo Paganotti ${ }^{4}$
}

(Submitted June 2015; Reviewed September 2015; Accepted December 2015)

\begin{abstract}
Current standards and guidelines for the design and installation of perimeter-fixed suspended ceilings are briefly reviewed and a summary of common damage in recent earthquakes is provided. Component failure fragility curves have been derived following experiments on typical NZ suspended ceilings, considering loading in tension, compression and shear. A simple method to analyse perimeter-fixed ceilings using peak floor acceleration (PFA) is described, allowing for ceiling system fragility to be obtained from component fragilities. This is illustrated in an example of a 5 storey building. It was found that single rivet end-fixings and cross-tee connections were the most critical elements of the ceilings governing the system capacity. In the design examples it was shown that ceilings at different elevations of the structure showed different probabilities of failure and larger ceiling areas with heavier tiles were most susceptible to damage.
\end{abstract}

\section{INTRODUCTION}

Non-structural elements (NSEs) in a building (also sometimes referred to as secondary elements) are components, which despite adding to building design dead loads, do not always contribute to the resistance against design actions. NSEs are indispensable because without them buildings are incomplete and cannot function as intended. While the load resisting structural components provide strength and stiffness to a building, NSEs are required to provide heat/sound insulation, compartmentalization, and protection from sun/rain which are vital in making the building inhabitable. Some of the most common NSEs in residential, as well as commercial buildings are ceilings, roofs, partitions, claddings, façades, windows, parapets, canopies, chimneys etc. Other movable components in buildings which contribute to the live load (e.g. furniture, appliances, equipment etc.) are generally categorised separately as contents.

NSEs and building contents make up a considerable 70-80\% of the total construction cost in commercial buildings [1]. In recent earthquakes, damage to NSEs has been reported to be significant (more so than the structural damage) [2-4]. Predictions using risk assessment methods have also suggested that the economic implication from non-structural damage is generally more significant than those of structural damage. For example, Bradley et al. [5] conducted a detailed component based seismic loss estimation on a typical office building in New Zealand and found that the direct repair cost of NSEs amounted to $44 \%$ of the total direct loss, which is higher than the structural loss $(25 \%)$ and contents $(31 \%)$. Among the NSEs, two major contributors were partitions (20\%) and ceilings (14\%)

When business downtime is included in the comparison, the criticality of NSEs is further elevated. In the 2010-2011 Canterbury earthquake sequence, many buildings remained unoccupied weeks after the event due to non-structural damage despite the building retaining its structural integrity. Observations from recent earthquakes have shown that if buildings do not collapse, it is mainly the NSEs and contents which dictate the extent of downtime. Even in the 2013 Seddon earthquake, which induced only minor-moderate level of shaking in Wellington, there was significant damage to NSEs [6]. The relatively new BNZ building suffered severe damage to its suspended ceilings requiring building closure for several weeks despite no significant structural damage.

In addition to significantly contributing to direct financial loss and downtime, damage to NSEs and contents can also be a life threat. For example, the collapse of ceiling boards led to loss of four lives in the 2011 Tohoku (Japan) earthquake [7, 8]. Similarly, collapse of parapets was the cause of some of the fatalities in the 2011 Christchurch earthquake and the extensive collapse of parapets, chimneys, canopies, façades and ceilings reported in the 2010 Darfield earthquake [3] could easily have caused loss of life or serious injury had the quake occurred at a different time of day.

In order to minimise such losses in earthquakes, it is necessary to realise the importance of designing NSEs to withstand design level earthquakes. This requires a clear understanding of the capacity of the NSEs and defining the limits of their use to meet design seismic demand in different locations. The main purpose of this paper is to provide a simple and practical method for the evaluation of the impact of floor acceleration on typical perimeter-fixed suspended ceilings currently designed and used in New Zealand. According to the principles of capacity design, a system is only as strong as its weakest member. Once the weakest element reaches its capacity, the system is considered a failure. Hence, the method of observation of ceilings in this study is the evaluation of its components to identify the weakest link. For this purpose, a series of tension-compression tests were conducted on components of a typical suspended ceiling in New Zealand. Results from these experiments were used to derive fragility curves for each ceiling component leading to identification of the weakest members. In the next phase of the study, perimeter-fixed suspended ceilings of various size and weight were designed based on current available guidelines. The component fragility curves were then used to evaluate the probability of failure in the designed ceilings when subject to

\footnotetext{
1 Professor, University of Canterbury, Christchurch, rajesh.dhakal@canterbury.ac.nz (Member)

2 Associate Professor, University of Canterbury, Christchurch, gregory.macrae@canterbury.ac.nz (Member)

3 Corresponding Author, Postgraduate Student, University of Canterbury, Christchurch, atefeh.pourali@pg.canterbury.ac.nz

4 Former visiting Masters student from Politecnico Di Milano
} 


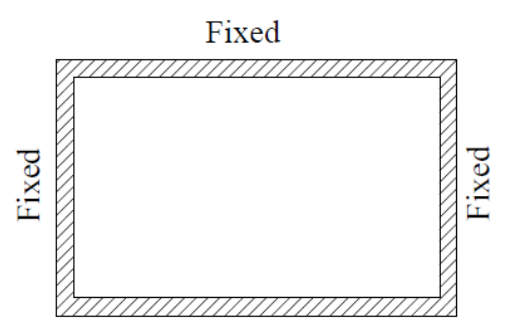

Fixed

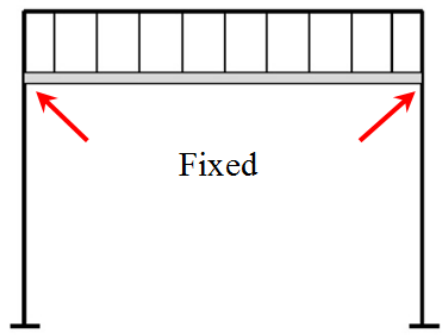

(a) Fixed-fixed
Fixed

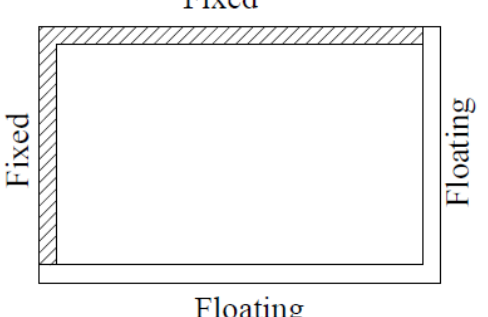

Floating

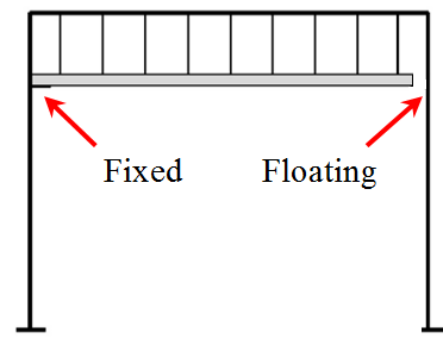

(b) Fixed-floating

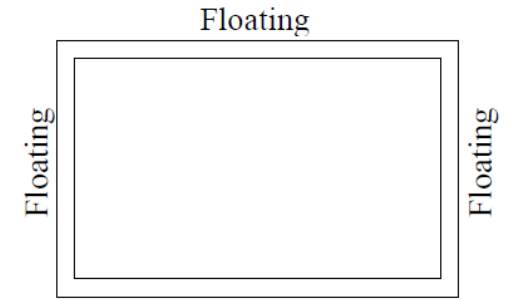

Floating

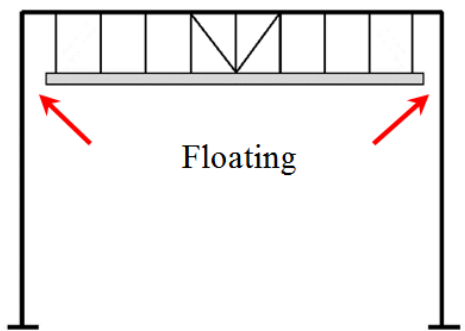

(c) Floating

Figure 1: Schematic of Different Ceiling Systems.

acceleration as intensity measure. These evaluations provide an insight into the level of reliability of current perimeterfixed ceilings at serviceability and ultimate limit states.

The objectives of this paper can be summarised in the following questions:

(i) What standards or guidelines exist for suspended ceiling systems?

(i) What damage has been observed in the past?

(ii) What is the capacity of typical ceiling components?

(iii) How do ceiling components contribute to the overall ceiling system performance?

(iv) Comparing examples of different ceiling systems, what parameters result in a more susceptible response?

\section{SUSPENDED CEILING SYSTEMS IN NZ}

\section{Typical Layout}

Suspended ceilings are architectural components sensitive to both acceleration and displacement [9]. Depending on the structure and load bearing system, they are categorised as perimeter-fixed, with one or more sides connected to the adjacent wall as shown in Figure 1a or 1b, or floating systems which have no connection to any walls but are braced to the floor above, as shown in Figure 1c.

The fixed-fixed system of Figure 1a was recommended by many ceiling supplier systems for small ceilings until recent earthquakes, with force designed to be carried on one or both sides. However, in such systems any relative movement of the adjacent walls applies force to the ceiling system. Such movement may occur during the dynamic motion of the structure and walls, or due to beam elongation effects.

More recently, to avoid these issues, the fixed-floating approach in Figure 1b has been recommended (e.g. by USG [10]). This system also works well for small ceilings because it avoids any forces due to relative wall movement, as long as the gaps on the floating sides remain open. A thin covering is placed over the separation to provide an acceptable appearance. Here, all inertial forces are transferred to the perimeter fixings on the fixed sides, making these connections the most vulnerable components of the system.

For larger ceilings, the ceiling grid may not to be strong enough to carry the expected lateral forces, so additional ceiling bracing to the floor above may be used while fully separating the ceiling perimeters from the structure. For instance, ASTM E580 [11] mandates the application of lateral restraints for all suspended ceilings in seismic category D-F, should the size of the ceiling exceed $1000 \mathrm{ft}^{2}\left[93 \mathrm{~m}^{2}\right]$. The braced ceiling, also referred to as a floating ceiling, or fully separated ceiling, shown in Figure 1c, carries horizontal force due to the horizontal accelerations of the floor above through the braces and it is disconnected from the surrounding walls.

A typical suspended ceiling consists of a grid system of inverted T-shaped beams assembled perpendicular to each other forming square or rectangular grids for the lay-in tiles to sit on (Figure 2a). The grid system consists of $3600 \mathrm{~mm}$ long main tees and $600 \mathrm{~mm}$ or $1200 \mathrm{~mm}$ long cross tees. Main tees are generally placed perpendicular to the upper floor joists or in shorter direction. For cases where the length of the main tee direction exceeds $3600 \mathrm{~mm}$, they may be extended via splices. Cross tees pass through special slots in the main tee webs and are connected to the next cross tee via click-fit clips (Figure 2c). No additional mechanical fasteners are used in the assembly of the grid system itself. On the fixed ends, the grid system is connected to the perimeter angle fastened to the surrounding walls using mechanical fixtures such as rivets, screws or proprietary clips. The lay-in tiles are not fastened to the grids but rather sit freely on the inverted tee flanges. AS/NZS 2785:2000 [12] recommends the use of retainer clips to control the upward movement of the tiles. However, these clips are not commonly used due to installation difficulties. 


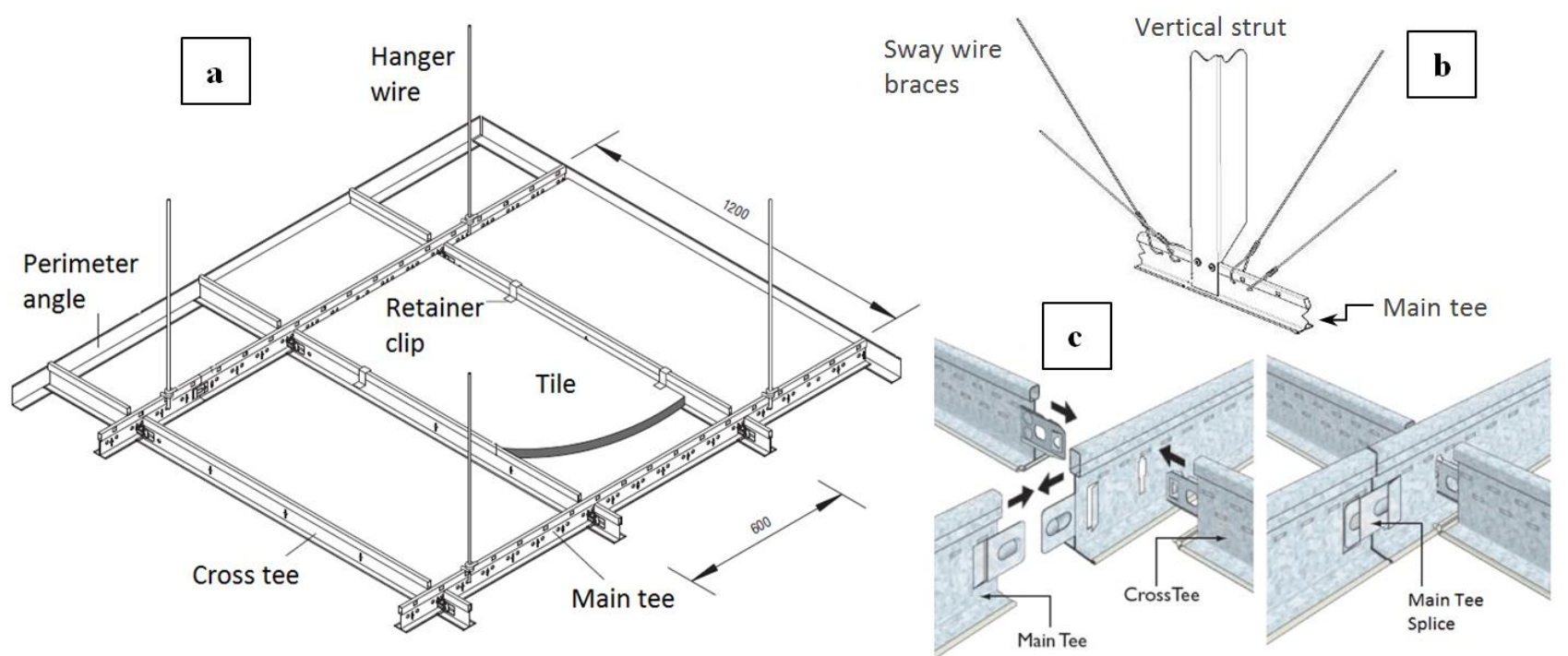

Figure 2: (a) Typical suspended ceiling components [13]; (b) Typical back bracing options [10] \& (c) tee joint details [14].

The grid system is hung from the structure above via hanger wires connected to main tees at $1200 \mathrm{~mm}$ intervals. The hanger wires are a minimum of 12-gauge galvanized, soft annealed mild steel wire [15]. The wire must be wrapped around itself a minimum of 3 full turns within $75 \mathrm{~mm}$. These vertical wires don't have any lateral resistance but their application, particularly on perimeters, has proven advantageous in limiting the spreading of grid ends and consequent damage during earthquakes. For this purpose all terminal ends of grid members should be supported via vertical hanger wires at a maximum $200 \mathrm{~mm}$ from each wall or ceiling discontinuity. Ceilings designed for seismic design categories $\mathrm{D}, \mathrm{E}$ and $\mathrm{F}$ should have a minimum perimeter support ledge of $50 \mathrm{~mm}$ and grid ends are required to have a clearance of $18 \mathrm{~mm}$ from the perimeter member [11]. The bracing can consist of four diagonal wires and a vertical strut performing as a compression post (Figure 2b). Diagonal channel or strut members can also be used instead of the wires.

\section{Current Design/Installation Approach}

There are a number of standards and documents specific or relevant to the design or installation of suspended ceilings [16]. The following documents are available in New Zealand:

- (NZS 1170.5:2004) Structural Design Actions, Earthquake Actions, New Zealand [17].

- (AS/NZS 2785:2000) - Suspended Ceilings: Design and Installation [12].

- (NZS 4219:2009) - Seismic performance of engineering systems in a building [18].

- (NZS 4541:2013) - Automatic Fire Sprinkler Systems in a building [19].

- (Ministry of Works PW/81/10/1:1985) - Guidelines for the Seismic Design of Public Buildings: Appendix D Suspended Ceilings and Associated Fittings and Fixtures [20].

- (AS/NZS 1170.1:2002) - Structural design actions Permanent, imposed and other actions [21].

- (AS/NZS 1530.3:1999) - Methods for fire test on building materials, components and structures - Simultaneous determination of ignitability, flame propagation, heat release and smoke release [22].

- (AS 2946:1991) - Suspended ceilings, recessed luminaries and air diffusers - Interface requirements for physical compatibility [23].
Some other documents and standards providing guidelines for suspended ceilings in the United States include:

- FEMA E74 - Reducing the Risks of Non-structural Earthquake Damage - A Practical Guide [9].

- ASCE/SEI 7-10 - Minimum Design Loads for Buildings and Other Structures - Chapter 13 Seismic Design for Non-structural Components [24].

- ASTM C635 - Standard Specification for the Manufacture Performance and Testing of Metal Suspension Systems for Acoustical Tile and Lay-in Panels [25].

- ASTM C636 - Standard Practice for Installation of Metal Ceiling Suspension Systems for Acoustical Tile and Layin Panels [15].

- ASTM E580 - Standard Practice for Installation of Ceiling Suspension Systems for Acoustical Tile and Lay-in Panels in Areas Subject to Earthquake [11].

- ASTM E1414-11 - Standard Test Method for Airborne Sound Attenuation between Rooms Sharing a Common Ceiling Plenum (Two room method) [26].

- CISCA - Guidelines for Seismic Restraint for Direct Hung Suspended Ceiling Assemblies - Seismic Zones 3-4 [27].

Some of the key contributions of these documents are listed below:

(NZS 1170.5:2004) [17] New Zealand standard for design of structures subject to earthquake actions provides a section for determining the seismic demand on parts (NSEs) including suspended ceilings. The horizontal acceleration coefficient for parts according to NZS 1170.5:2004 [17], is an expression consisting of the following factors: i) site hazard coefficient which is a factor of site hazard, spectral shape factor and the probability of occurrence of the seismic event relevant to the limit state, ii) height coefficient which depending on the location of the part up building height can vary between 2 and 3 (Figure $3 \mathrm{~b}$ ) and iii) part spectral shape factor which varies between 0.5 and 2 based on the period of the part (Figure $3 a$ ).

The detailed design of ceilings is carried out based on the recommendations of ceiling manufacturers which comply with these standards. The general trend in current manufacturers' guidelines $[28,10]$ is to design ceilings to satisfy the serviceability limit state.

AS/NZS 2785:2000 [12] Australia and New Zealand Standard for suspended ceilings sets out the minimum requirements for the design, construction, installation, maintenance and testing of internal and external non-trafficable suspended ceilings for use in commercial, industrial and residential buildings. The 
(a)

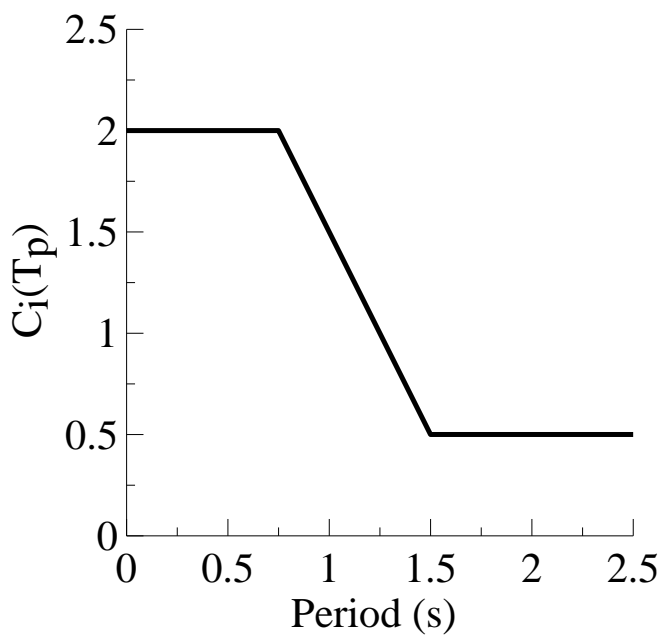

(b)

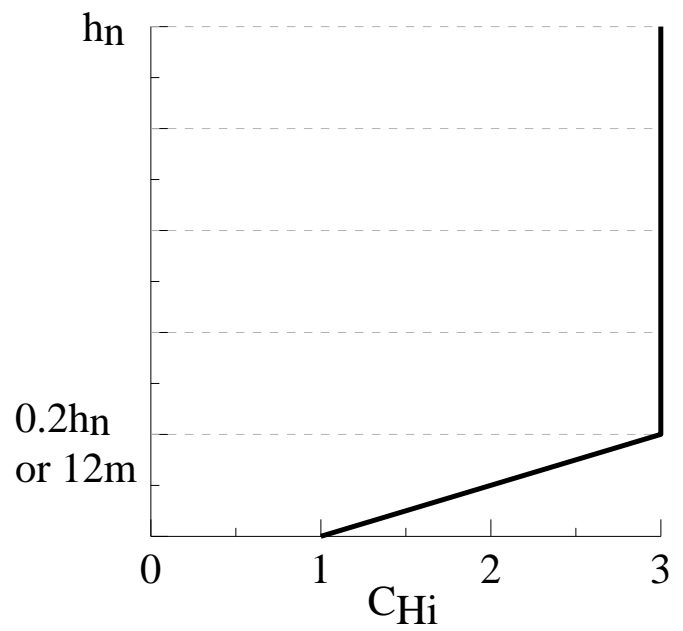

Figure 3: (a) Part spectral shape coefficient; (b) height coefficient (right) [17].

standard includes the design loads, definition of limit states and installation recommendations. However, the recommendations are mainly qualitative rather than specifying quantitative limits. In many cases the users are referred to the proprietary manufacturers' specifications.

Suspended ceilings are outside the scope of NZS 4219:2009 [18]. However this document provides minimum clearance limits to be applied between components of suspended ceiling system and other services and equipment within ceiling plenum.

ASCE7-10 [24] in Chapter 13 provides an expression for the seismic design force taking into account component's importance and amplification factors, spectral acceleration for short period, component's response modification factor, height in structure and component's operating weight.

ASTM E580 [11] sets out minimum requirements for the installation of suspended ceilings. This document which is mainly adopted by most proprietary guidelines, provides quantitative requirements and limits for grid members and connections load capacity, grid spacing, bracing, maximum allowable weight, and layout and details for installation. The requirements are provided for areas of light to moderate, as well as high seismicity.

Proprietary manufacturers also provide guidelines specific to their products $[28,10]$. These documents provide brief design methods and installation techniques which need to be strictly followed in case the final work requires inspection to be signed off.

Based on NZS 1170.5:2004 [17], suspended ceilings are mainly designed for serviceability limit state (SLS) unless they are located in buildings of high post-disaster significance such as hospitals and police stations or in case they cover egress areas. However, the performance of suspended ceilings in recent seismic events has proven that damage to suspended ceilings can pose a life threat and cause considerable financial loss $[3,29]$.

Suspended ceilings do not exhibit a great level of ductility. Hence the point where the system loses its originally intended operation -SLS- and the point where it loses integrity and undergoes collapse, thereby endangering occupants -ultimate limit state ULS- are close. Therefore, the reconsideration and thorough evaluation of design and installation practices in New Zealand seem inevitable and highly beneficial in reducing future losses.

\section{Seismic Performance}

Based on Dhakal [3], following the magnitude 7.1 Darfield earthquake in September 2010 in New Zealand, ceiling damage was observed both in low-rise residential houses and commercial buildings. Damage was less significant in residential ceilings which were typically plasterboard type. Ceilings in commercial buildings were the suspended type which is discussed in this paper. The damage observed in these types of ceilings included dislodging and breaking of the tiles, failure of the ceiling grid members and connections, failure of perimeter angles and damage to ceiling tiles due to interaction with the services (Figure 4). In a crude approximation, $10 \%-15 \%$ of commercial/industrial buildings incurred ceiling damage to different extents.

The other type of grid damage occurred in one-way suspended ceilings where tiles are supported by main tees spanning one way and hung from the structure above. There are typically no transverse tees. As soon as the first tile fails the system loses integrity and grid members are free to spread resulting in failure of adjacent tiles (Figure 4e).

A large portion of grid damage observed was concentrated around perimeters which results from the main tee or cross tee either being compressed into the rigid surrounding structure or losing support on the perimeter angle around the ceiling. Loss of support can be due to the absence of proper perimeter hanger wires, absence of rivets to connect the grid member to the angle or failure of the rivet itself (Figures $4 b$ \& 4f). Perimeter fixings are especially prone to damage as they transfer the largest inertial force from the suspension system to the rigid supporting structure. As acceleration is applied to the ceiling, the inertial force induced by the seismic mass increases throughout the length of the grid carrying ceiling tiles.

The Magnitude 6.3 Christchurch earthquake in February 2011 resulted in significant damage in both high-rise and medium height buildings. Tall buildings due to the nature of the event suffered both structural and non-structural damage but in lowrise structures the damage was in most cases non-structural while the structure remained intact. Among these nonstructural elements, ceilings were conspicuous as the most severely damaged NSEs according to Dhakal et al. [29]. Similar forms of damage in suspended ceilings were observed in this earthquake compared to 2010 Darfield earthquake. A combination of smaller ceilings and lighter tiles was reported to result in lower demand on the grid members and connections, which led to safer ceilings [3, 29]. 

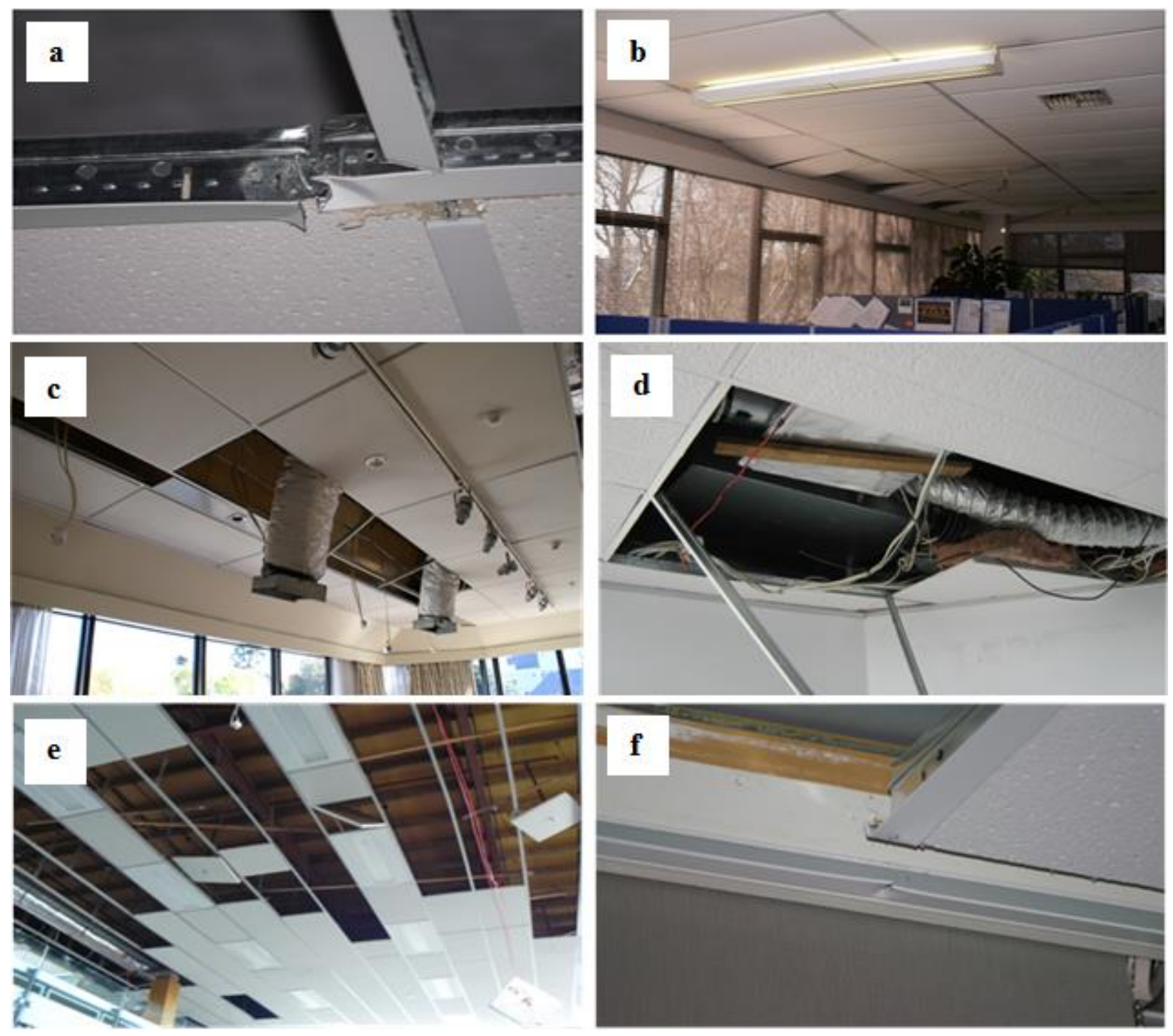

Figure 4: Failure due to (a) main tee splices; (b) perimeter fixings; (c \& d) services support; (e) grid spreading; and (f) perimeter fixing damage [3].

Services and fire sprinklers are frequently reported as one of the causes of ceiling damage. In July 2013, following the magnitude 6.5 earthquake centred in Cook Strait, widespread non-structural damage was reported in the BNZ Harbour Quays building in Wellington. The suspended ceilings and sprinkler pipes were extensively damaged and showed signs of large deformations (Figure 5). Based on reports, it took nearly 6 months before the tenants (BNZ) could reoccupy the building, resulting in large financial loss due to downtime as well as repair [30].

In many damage cases observed, ceilings and services either lacked suitable seismic design, or were not correctly installed. The extent and nature of the loss due to suspended ceiling failure observed in recent earthquakes is an indication of the significance of the issue. These observations highlight the need for a thorough investigation, and enforcement of consistent methods for design and installation of NSEs and suspended ceilings in particular.

There have been a number of research projects investigating the seismic fragility of suspended ceilings and performance of different configurations of ceiling system. One of the early experiments done by ANCO Engineers Inc. [31] on a prototypical suspended ceiling concluded that the most common locations for damage in suspended ceiling systems were around the perimeter of a room at the intersection of the walls and ceilings, where the grids buckle or detach from the perimeter angle. Their research also showed that pop rivet installation was more influential than sway wires and that sway wire braces, if installed with perimeter fixing, will not be active in the system's lateral restraint.

Rihal et al. [32] investigated the effectiveness of current building code provisions and installation practices for braced and unbraced suspended ceilings with and without partitions in a series of dynamic tests. According to their results, specimens with a vertical strut showed less uplift which occurs due to the vertical excitation in ceilings. Extensive damage to the ceiling system was observed at unattached (floating) perimeters. The addition of vertical hanger wires located at cross tees, 8 inch max from unattached perimeter, prevented tiles from crashing down, but damage was instead caused by pounding of cross tees to perimeter angles.

Badillo-Almaraz et al. [33] conducted fragility studies on suspended ceiling systems. In their full-scale earthquakesimulator testing they evaluated the effect of size and weight of tiles, use of retainer clips, installation of compression posts, and physical condition of grid components on the performance of ceilings. Four limit states were proposed to evaluate the 

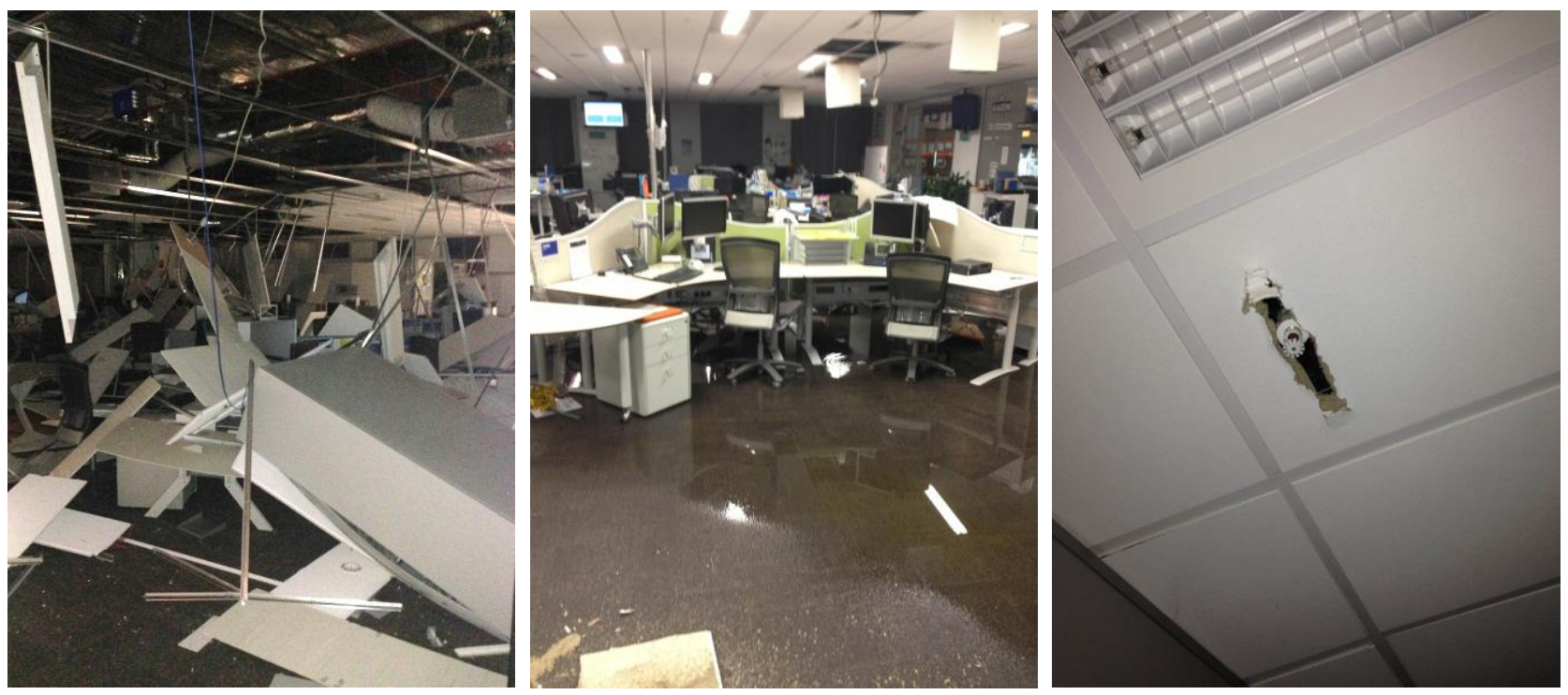

Figure 5: Damage in BNZ building (Photo: Terry Johnson).

damage observed in the systems and the threshold peak floor accelerations associated with each limit state were found.

In a series of studies by Gilani et al. [34, 35] and Glasgow [36], an experimental procedure and a performance matrix based on limit states were developed to evaluate and qualify innovations and quantitatively assess the efficacy of various code prescribed design and installation requirements. A fragility curve was derived for ceiling tile failure as one of the damage states. The use of intermediate duty main runners in high seismic regions was also tested through a case study which showed that the substitution of intermediate for heavyduty main runners does not adversely affect the seismic response of the system. The terms intermediate and heavyduty refer to gird members of various capacities. These categories are defined based on the maximum load on the grid associated with an allowable midspan deflection [15].

Ryu et al. [37] published a report on full scale shake table tests on large area suspended ceilings using 3D motions. In their tests they compared the seismic response of suspended ceilings with different areas $(6.1 \mathrm{~m} \times 15.2 \mathrm{~m}, 6.1 \mathrm{~m} \times 6.1 \mathrm{~m}$, $4.8 \mathrm{~m} \times 4.8 \mathrm{~m}$ and $3.6 \mathrm{~m} \times 3.6 \mathrm{~m}$ ). They also investigated the effect of tile weight, multidirectional excitation and end fixing type. Three different failure mechanisms were observed during tests and fragility curves were derived for four damage states. Based on their results, the observed failure was concentrated on connections rather than grid body. Simplified uniaxial numerical models were also developed to track the behaviour of the system.

\section{METHODOLOGY}

\section{Tests on Components and Connections}

\section{Test Setup}

A series of destructive static tests were carried out on components of a typical suspended ceiling system manufactured by two of the major ceiling providers in New Zealand (T1 for Type 1 and T2 for Type 2) [38, 39]. The experiments focused on grid members -main tees and cross tees- as well as connections including cross tee connections, main tee splices and end fixing rivets. Tension, compression and shear tests were carried out on the $100 \mathrm{kN}$ Avery Universal Testing machine and the $250 \mathrm{kN}$ Instron Universal Testing machine at the University of Canterbury (Figure 6a). The first machine provides loading at a range of $50 \mathrm{kN}$ by 0.1
$\mathrm{kN}$ divisions and the second machine applies load at a range of $5 \mathrm{kN}$ by $0.01 \mathrm{kN}$ divisions. For tension and compression tests on members, the Avery Universal testing machine was used. The Instron Universal testing machine was used to conduct all other tests on connections. The choice of machine depended on maximum load searched as well as the length of the specimens tested. The loading rate for connection tests was lower than the member tests as connections were expected to fail at an earlier stage.
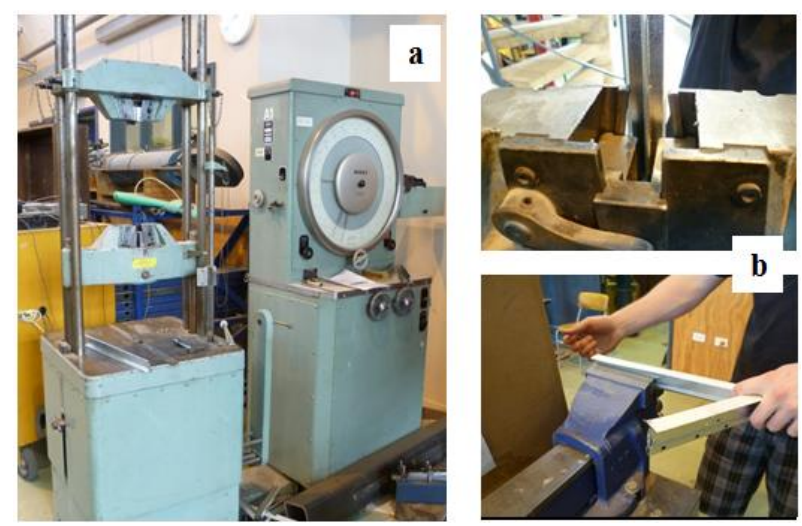

Figure 6: (a) Test apparatus and (b) preparation of specimens.

In order to provide a good grip between the specimens and the test machine, the two flanges of the inverted T-shape section on either end of the specimens were removed and the web was compressed (Figure 6b). In connection tests, specimens consisted of a main tee and two cross tees connected through the main tee slot (Figure 7).

The tensile tests on grid members were standardized by AS/NZS 2785:2000 [12]. However there is no standard suggesting methods for testing connections, which are suspected to be the weakest part of the ceiling system. Also, there is no specific test standard for compression. In this case the design of the experiment is very important as the test configuration can easily affect the results. Therefore, a rig was constructed (Figure 7a) for compression tests which not only maintained the joint position during the test, but also allowed for the compressive action to take place without restraining the system too greatly, as this would potentially give higher values. The rig consisted of a piece of laminated veneer 


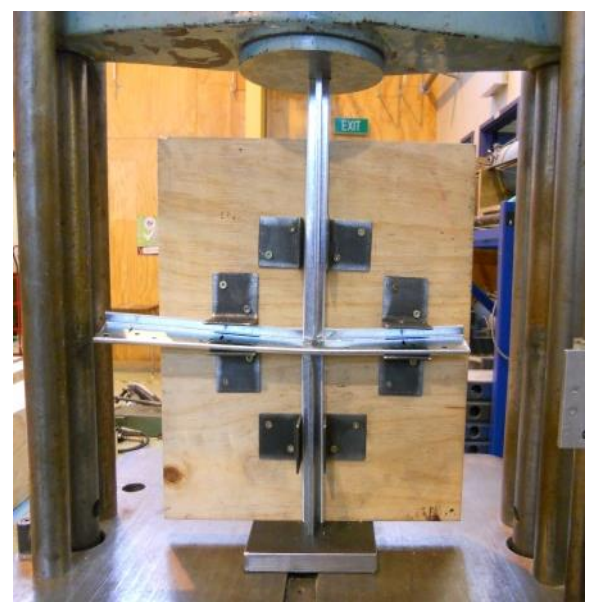

(a)

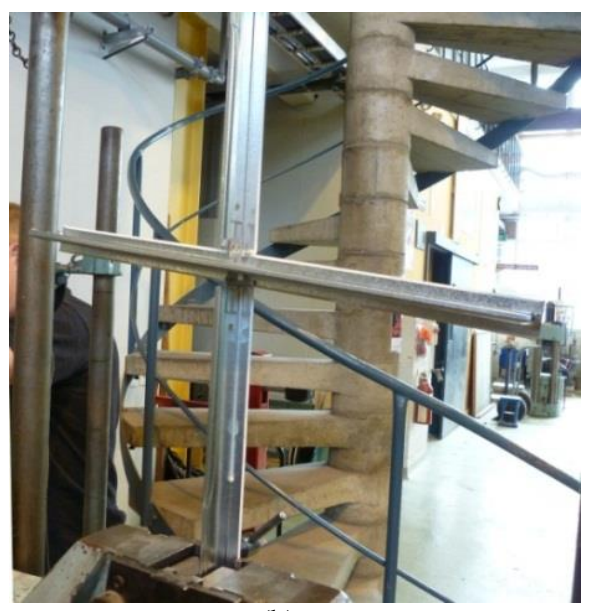

(b)

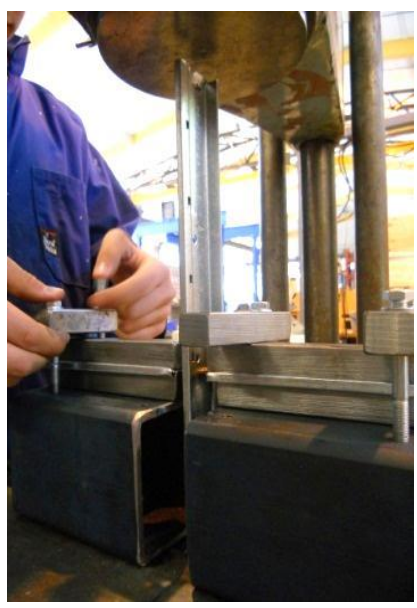

(c)

Figure 7: Setup for (a) Compression, (b) Tension and (c) Shear test.

lumber, with a thickness of $15 \mathrm{~mm}$. Eight $50 \mathrm{~mm} \times 50 \mathrm{~mm} \times$ $2.5 \mathrm{~mm}$ steel angles of $50 \mathrm{~mm}$ length were screwed to the surface of the lumber as shown in Figure 7a. The angles kept the main tee in the horizontal position while the vertically positioned cross tees were being loaded by the machine. The angles simulated the effect of ceiling tiles, as they help with the orthogonality of fully installed ceiling systems.

Cross tee connections were also tested in shear. This loading condition was created using an in-plane force which simulated the effect of tile pressure and impact on the connection. For this purpose a different rig was created which consisted of two steel members fixed to the testing machine and accommodating two cross tees in horizontal position. The main tee is placed perpendicular to the cross tees and pushed down (Figure 7c).

\section{Test Specimens}

The length of each specimen was approximately $600 \mathrm{~mm}$, which is equal to the actual length of a short cross tee. This length was chosen to be as close as possible to the actual component's dimension while satisfying the limits imposed by the test facility. Specimens were subjected to gradually increasing static load. The failure point was identified as the point when the applied force started decreasing.

A minimum of ten specimens of every component type from each manufacturer were tested to make sure that the obtained test results were enough to statistically interpret the strength of all components tested. For tests on tee to perimeter angle connections $3.2 \mathrm{~mm}$ aluminium rivets were used. The cross sections and locations of the components tested are shown in Figures 8 and 9. Table 1 lists the components and number of specimens tested. The results from the component tests were used for derivation of fragility curves, which showed each component's probability of failure for a given force value.

Table 1: Number of tests.

\begin{tabular}{ccccc}
\hline No. & Component & Tension & Compression & Shear \\
\hline 1 & Main T member & 10 & 10 & - \\
2 & Cross T member & 10 & 10 & - \\
3 & Main T splice & 10 & 10 & - \\
4 & Cross T connection & 10 & 10 & 10 \\
5 & $\begin{array}{c}\text { T to perimeter angle } \\
\text { rivet connection }\end{array}$ & 40 & - & - \\
\hline
\end{tabular}

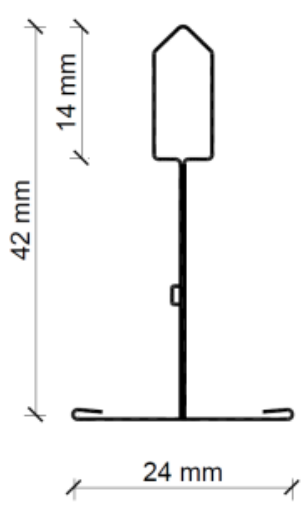

Type 1 Main tee

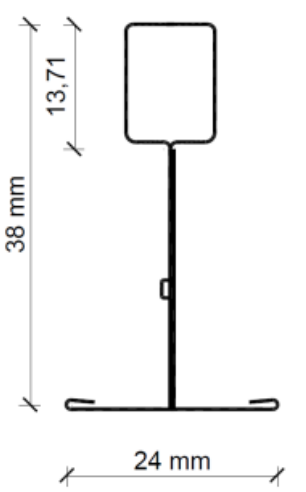

Type 2 Main tee

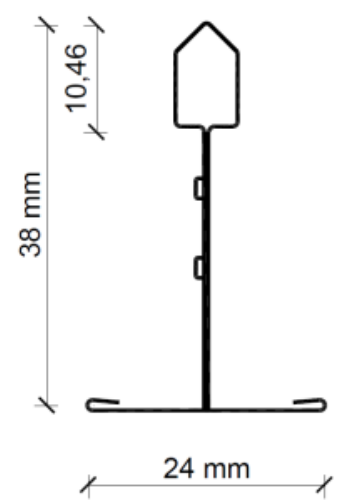

Type 1 Cross tee

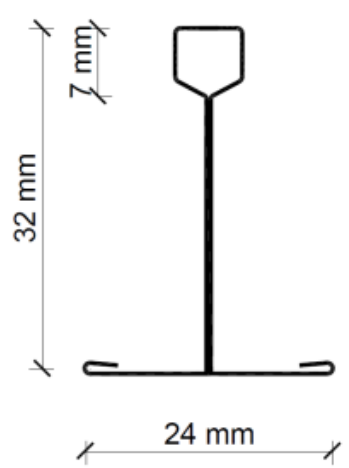

Type 2 Cross tee
Figure 8: Cross section view of test specimens from two manufacturers.

\section{Simplified Analysis of a Suspended Ceiling System}

Ceiling systems are acceleration sensitive NSEs, and consequently are designed for the peak acceleration they are subjected to. This acceleration differs from the one reaching the supporting structure both in intensity and characteristics and can be considered the response of the supporting structure to the ground motion. When the arriving strong ground motion interacts with a structure, and propagates to the respective floors of the building, its frequency content and intensity are modified by the building response. These changes vary from structure to structure based on the buildings dynamic properties (i.e. stiffness, mass and damping characteristics). Consequently, a ceiling system may be subjected to unique demands when installed in different structures, or even at 


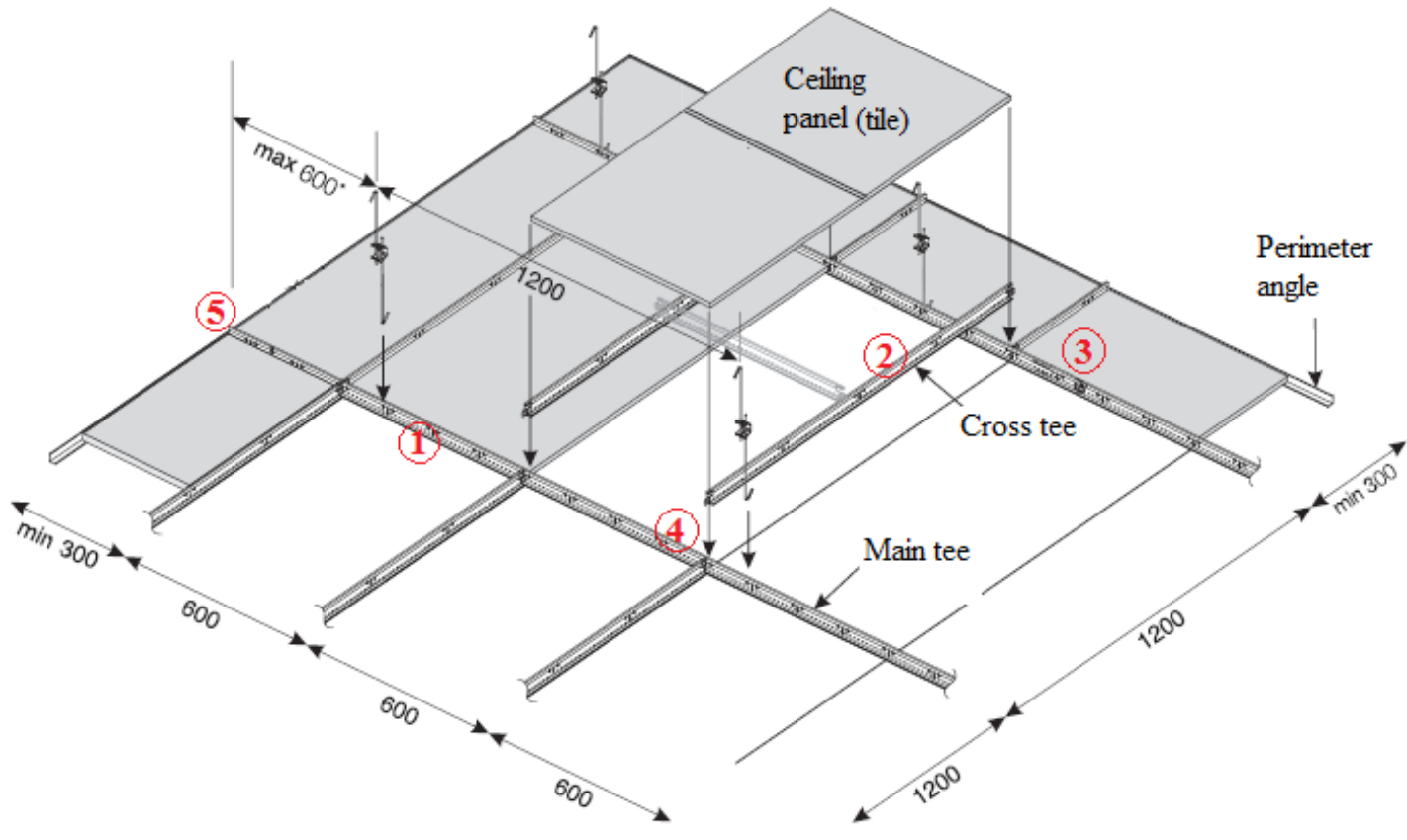

Figure 9: Components tested.

different elevations or parts of the same building. Therefore, ceilings should be assessed and designed for peak floor acceleration (PFA) rather than peak ground acceleration (PGA).

New Zealand Standard NZS 1170.5:2004 [17] in section 8 introduces $\mathrm{C}_{\mathrm{Hi}}$, a floor height factor of up to 3 , to be applied to the horizontal acceleration coefficient for NSEs supported at various elevations of a structure.
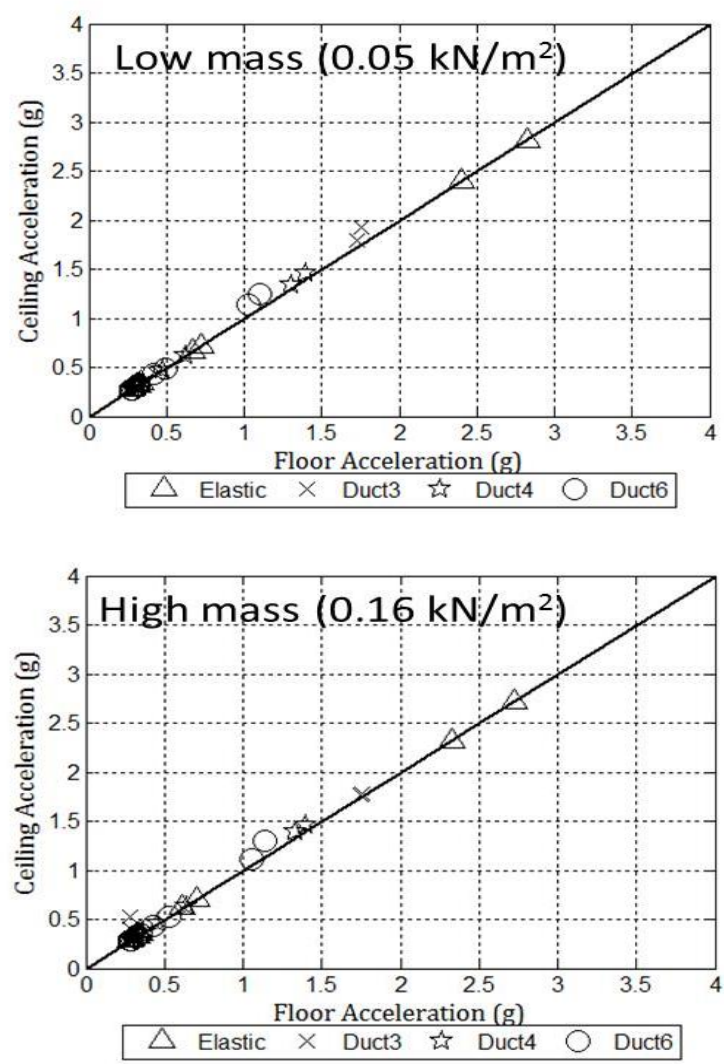

Figure 10: Perimeter-fixed ceiling acceleration vs. floor acceleration for light and heavy ceilings [41].
Analytical investigations by Singh et al. [41] showed that the negligible addition of mass from suspended ceilings compared to the total structure mass does not alter the dynamic properties of the floor and the building noticeably. It was also concluded that the typical connection between ceilings and perimeter structure is rigid enough to assume the input acceleration to the ceiling was equal to the floor acceleration (Figure 10)

The acceleration transferred to the level of ceiling is distributed among the ceiling components. As the ceiling itself has an inherent flexibility, the peak acceleration induced in various components of the system might vary from the PFA. New Zealand Standard NZS 1170.5:2004 [17] in section 8 recommends a spectral shape coefficient of 2 to be applied in calculation of the horizontal acceleration coefficient for parts with a natural period of less than 0.75 s. Pourali et al. [40] also showed that the acceleration recorded on various locations of the perimeter-fixed ceiling grid tested were up to 3.5 times larger than the PFA. Since the method used in this study is based on the capacity of ceiling grid joints, the acceleration used as the intensity measure in all fragility curves derived are the peak ceiling grid acceleration (PCGA) which is expected to be larger than the PFA.

Figure 11 shows the perimeter connections between the suspended ceiling grids and walls. The ceiling grids are riveted to wall supports on two adjacent ends and floating on the opposite ends. According to common practice, proprietary clips are recommended on free ends which only allow the grids to slide along their longitudinal axis and are fixed to the wall in the other directions. This forms some fixity on the floating ends which is schematically shown in Figure 11b. In this paper the effect of this partial fixity on the load path is overlooked and the load transfer is assumed direct and uninterrupted.

The seismic mass of the ceiling system is mainly associated with the ceiling tiles supported by the grids. It is assumed that these tiles perform like a rigid diaphragm and transfer the inertial force to the transverse tees as shown in Figure 12. In this figure longitudinal tees are assumed in the direction of loading and transverse tees are perpendicular to them. The force induced in transverse tees is transferred to longitudinal tees through a shear force equal to (m.S.l.a/2), where $m$ is the ceiling mass per unit area $\left(\mathrm{kg} / \mathrm{m}^{2}\right), l$ is tile length in the 
Rivet

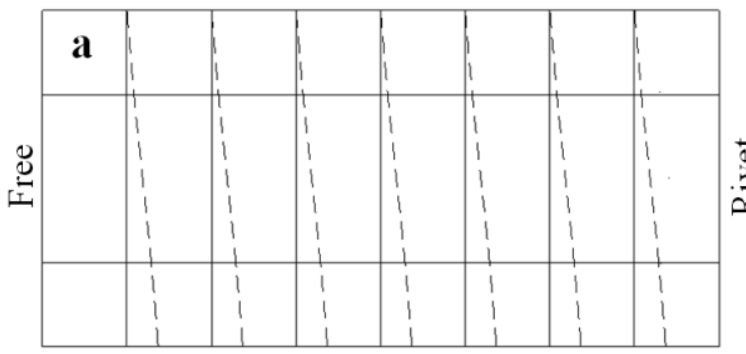

Free
Rivet

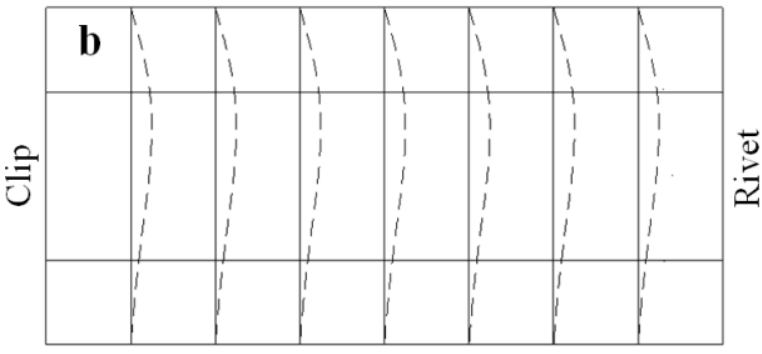

Clip

Figure 11: Schematic view of grid end fixings.

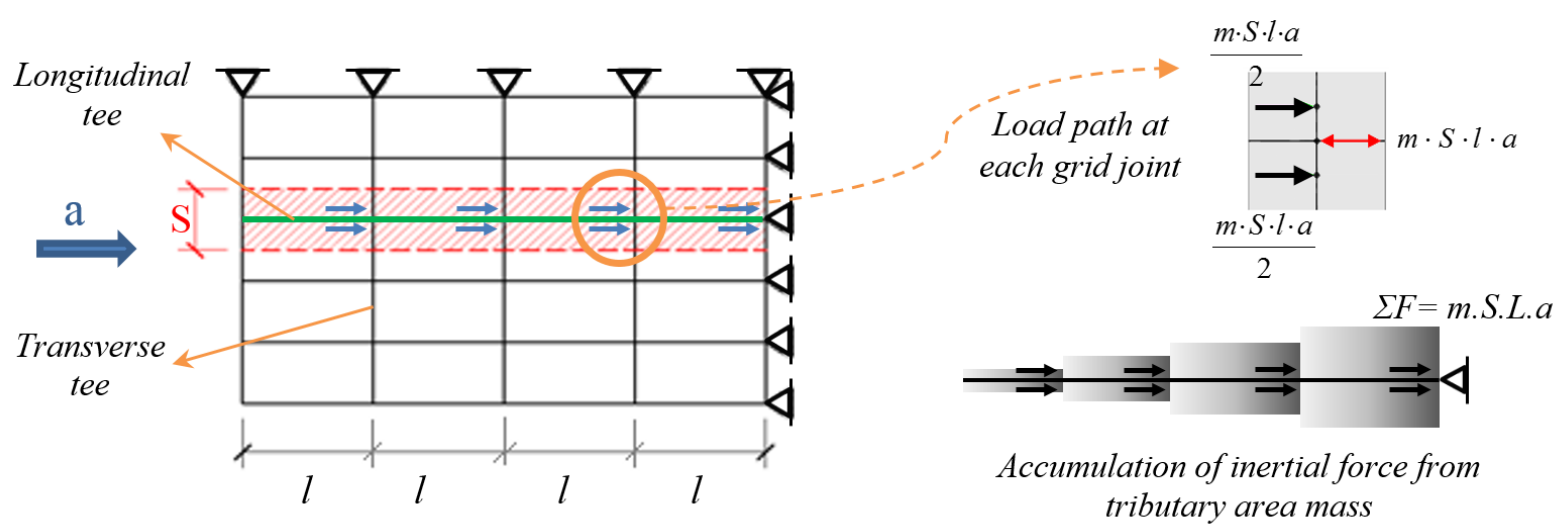

Figure 12: Schematic of load path on perimeter-fixed ceiling.

direction of loading $(\mathrm{m}), S$ is tee spacing $(\mathrm{m})$ and $a$ is the PCGA ( $\mathrm{g}$ ). The longitudinal tee at each node is subjected to an axial force of (m.S.l.a). It is possible to consider connections between grid members pinned and therefore gradually sum up the inertial force from all tiles at the grid joints. The inertial force accumulated in an end connection shown in Figure 12 can be expressed through Equation 1 where $(\mathrm{L}=\Sigma \mathrm{l})$ is the total tee length in the direction of loading $(\mathrm{m})$.

$$
F=m \cdot L \cdot S \cdot a
$$

These axial forces (both in compression and tension) form the demand on the grids and their spliced connections. Consequently any member of this force-transfer system with the lowest capacity undergoes yielding first and triggers failure. Therefore, the overall capacity of the ceiling system can be approximated by the capacity of the weakest element of the system. The results of component tests show that connections between the grid members undergo failure long before buckling occurs. Consequently, in this system, the buckling of the grids under compression has not been considered as a failure mode. Using these assumptions and the failure probability of components obtained through tests, fragility curves can be drawn for a certain ceiling size and weight.

\section{RESULTS AND DISCUSSION}

\section{Ceiling Component Test Results}

In tension tests on grid members, the failure loads characteristically caused tearing of the thin walls of the sections at the position of reduced area where the slots for the insertion of cross tees or hanging wires are situated (Figure 13a). In the case of main tee splices and cross tee connections, the failure happened in the connection clip and not the connected member itself (Figure 13b).

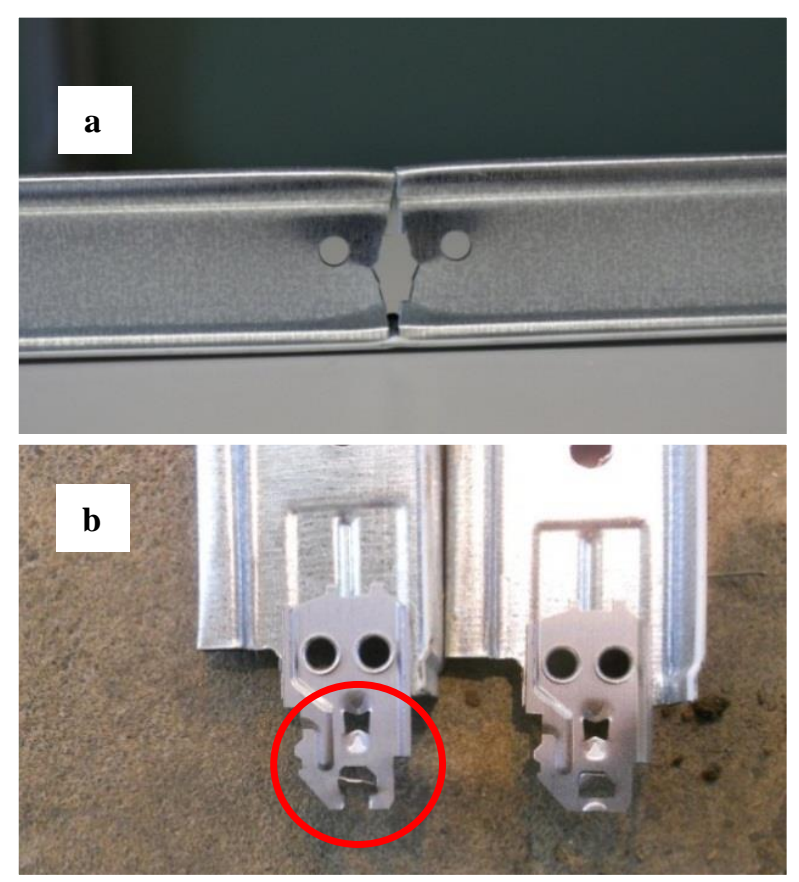

Figure 13: Failure modes in tension tests in (a) member; and (b) cross tee connection.

In compression tests on members, failure mode was the local buckling of the member at the location of reduced cross section (Figure 14a). In compression tests on splices, the failure load was much lower than ones of the member tests and the specimens all failed due to buckling, compression and deformation of splice connection. However, the failure loads of splices in compression were larger than the failure loads of splices in the tensile tests. This was due to the different nature 
of the failure process under two loading types. When under compression, before the two pieces of the splice connection came apart, there was a phase where the clips got crushed into each other. During this phase the connection still carried load and failure only happened after excessive buckling which finally broke the splice (Figure 14b).
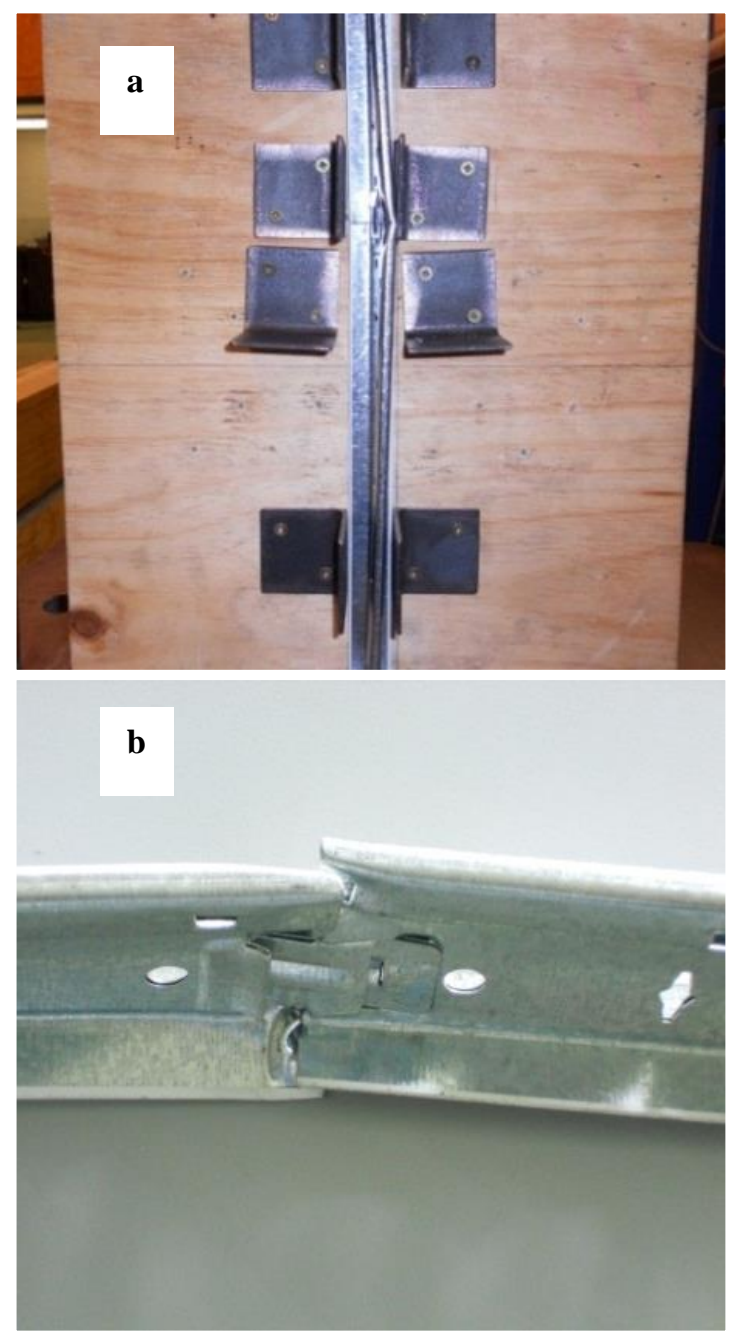

Figure 14: Failure in (a) main tee and (b) splice in compression.

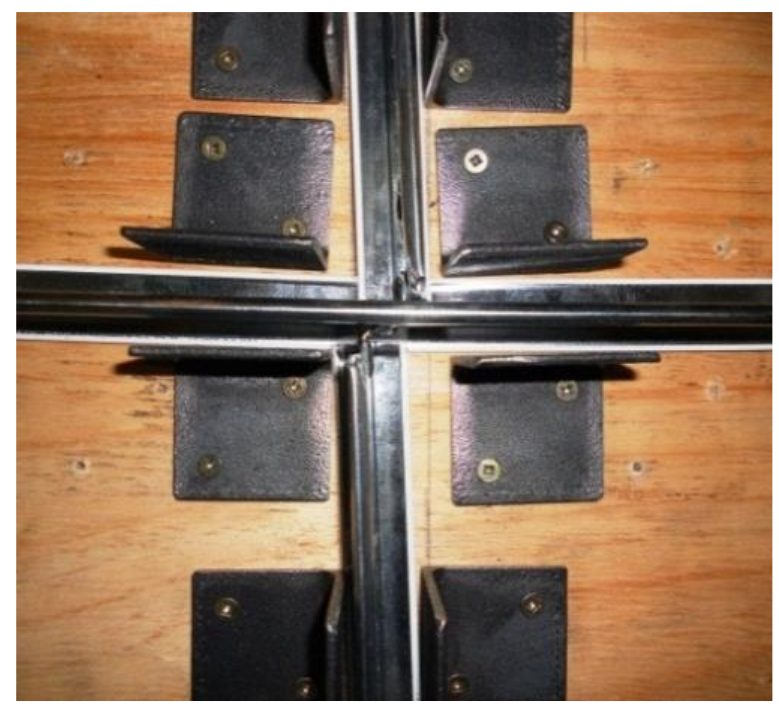

(a)
Compression tests on cross tee connections showed that the failure mode was buckling and distortion of the clips (Figure 15a). The values of failure loads in compression tests on cross tees were less than those of tensile tests. This made cross tee connections in compression so far the weakest member of the grid system.

Results of shear tests on cross tee connections showed that failure occurred when the connection clips were pulled out by the main tee (Figure 15b).

Rivet tests were carried out using a variety of positions for the rivet. These configurations varied in the distance of the rivet from the free edge of the connected elements i.e. perimeter angle and tee. The failure force was lower in cases where rivets were inserted close to the free edge of the tees, leading to tearing of the tee flange. When the rivet insertion point was shifted to further in the centre, failure force was increased and mode of failure changed to hole enlargement and rivet pullout. The highest value of failure load was found in the configuration where rivets were inserted near the edge of the perimeter angle and far inside the tee flange. This configuration provided good resistance both to hole enlargement and flange tearing (Figure 16). The last configuration tested was for connections with double rivets. The capacity of these connections was larger than all previous rivet connections tested, as expected. Table 2 shows the values of median and standard deviation for components tested and described above. A quick comparison shows that cross tee connections and single rivets were the weakest components of the system.

\section{Fragility Curves for Ceiling Components}

Following the completion of tests, values of median and standard deviation for each component (Table 2) were used to derive a cumulative distribution of failure loads. Both normal and lognormal distributions were derived for each component. To compare the appropriateness of the theoretical distribution functions, Kolmogorov-Smirnov (K-S) goodness-of-fit (GOF) tests were carried out. The K-S statistic (Dn,max) for the normal and lognormal distribution functions are reported in Figure 17 for comparison. In most cases, both distributions fit the data with similar error. In a few cases which showed some difference, lognormal distribution was found to be a better fit. Therefore, for consistency lognormal distribution was used for all component fragility curves.

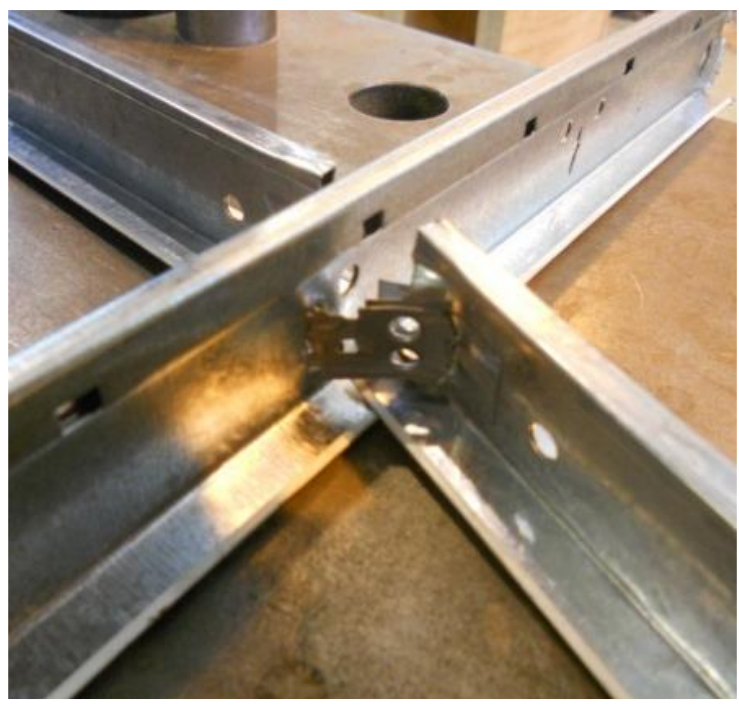

(b)

Figure 15: Failure in cross tee connection due to (a) compression and (b) shear. 
Table 2: Component test results.

\begin{tabular}{ccccc}
\hline \multirow{2}{*}{ Component Tested } & \multicolumn{2}{c}{$\begin{array}{c}\text { Median Failure Force } \\
(\mathbf{k N})\end{array}$} & \multicolumn{2}{c}{$\begin{array}{c}\text { Standard Deviation } \\
(\mathbf{k N})\end{array}$} \\
\cline { 2 - 5 } & Type $\mathbf{1}$ & Type 2 & Type 1 & Type 2 \\
\hline Main T in Compression & 3.86 & 3.47 & 0.15 & 0.13 \\
Main T in Tension & 9.4 & 8.35 & 0.11 & 0.10 \\
Cross T in Compression & 2.61 & 2.92 & 0.14 & 0.23 \\
Cross T in Tension & 8.55 & 8.15 & 0.18 & 0.08 \\
Cross T Connection in Compression & 0.73 & 0.86 & 0.10 & 0.11 \\
Cross T Connection In Tension & 1.04 & 1.29 & 0.27 & 0.37 \\
Main T Splice in Compression & 2.11 & 2.42 & 0.12 & 0.09 \\
Main T Splice in Tension & 1.09 & 1.02 & 0.07 & 0.05 \\
Cross T Connection in Shear & 1.00 & 0.80 & 0.11 & 0.15 \\
Single 3.2mm Rivet - Far & 0.69 & 0.77 & 0.06 & 0.04 \\
Single 3.2mm Rivet - Centre & 0.75 & 0.88 & 0.05 & 0.07 \\
Single 3.2mm Rivet - Near Edge & 0.97 & 0.97 & 0.09 & 0.06 \\
Double 3.2mm Rivets & 1.51 & 1.52 & 0.11 & 0.19 \\
\hline
\end{tabular}

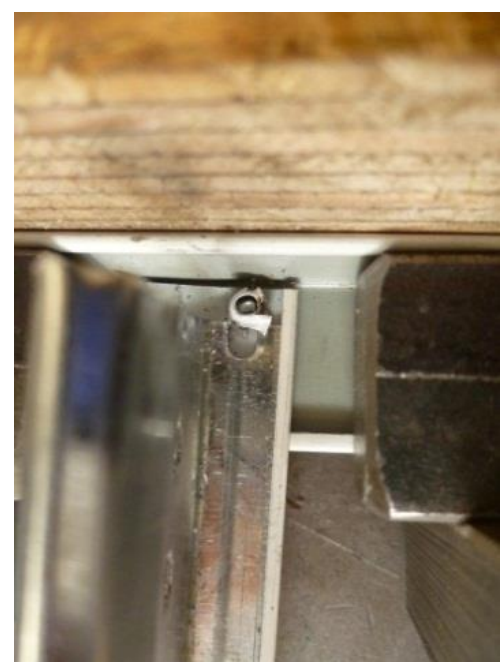

(a)

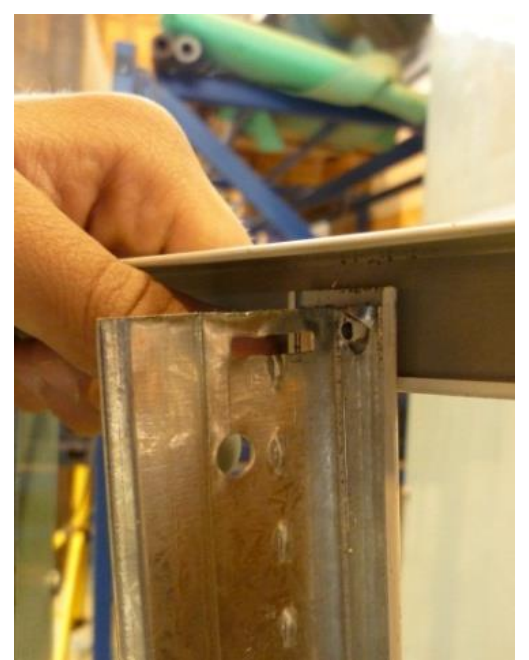

(b)

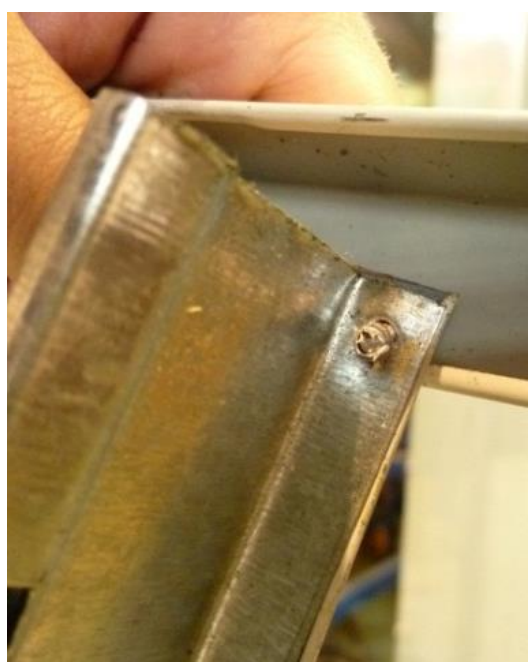

(c)

Figure 16: Failure modes in (a) far; (b) centre; and (c) near edge positions.

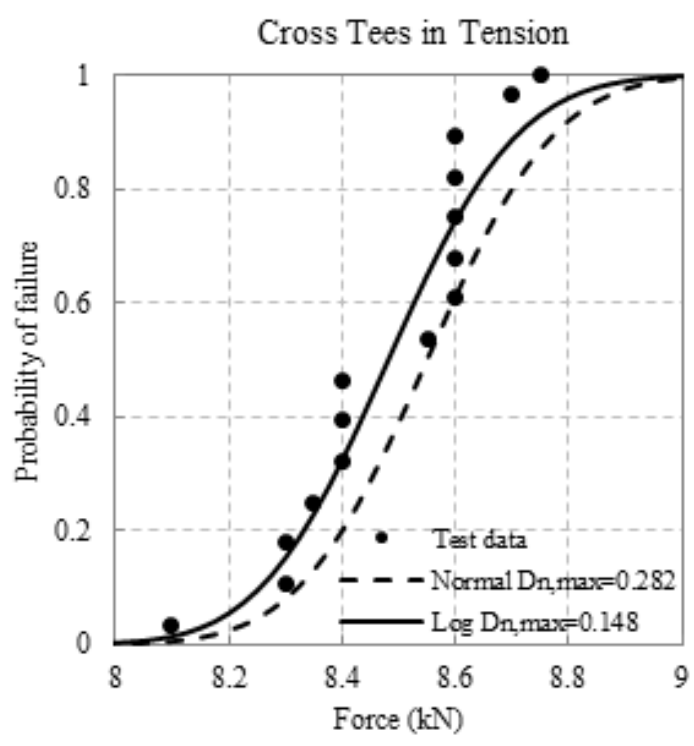

Figure 17: Fitted data vs. normal and lognormal distributions.
Figure 18 shows the fragility curves for all components tested under tension. Based on this figure, cross tee connections (shown as CT-con) were the weakest elements when under tension.

Comparing fragility curves of components tested under compression showed that i) cross tee connections were the weakest components under compression and ii) capacity of components in general was lower under compression than tension except for main tee splices which were discussed in previous section. Fragility curves for components tested under compression can be found in Figure 19.

Perimeter fixed suspended ceilings are connected to the surrounding walls on two adjacent sides via pop rivets. This type of rivet due to its financial and application advantages is most commonly used for fixing the ceiling grid to the perimeter angles. The capacity of various configurations of single and double $3.2 \mathrm{~mm}$ aluminium rivet connections under tensile loads (which causes shear in the rivet) were evaluated. As expected, using double rivets instead of one improved the capacity of the fixing. Figure 19 shows the fragility curves for $3.2 \mathrm{~mm}$ single and double rivets. The single rivets in this figure were in the centre position. 

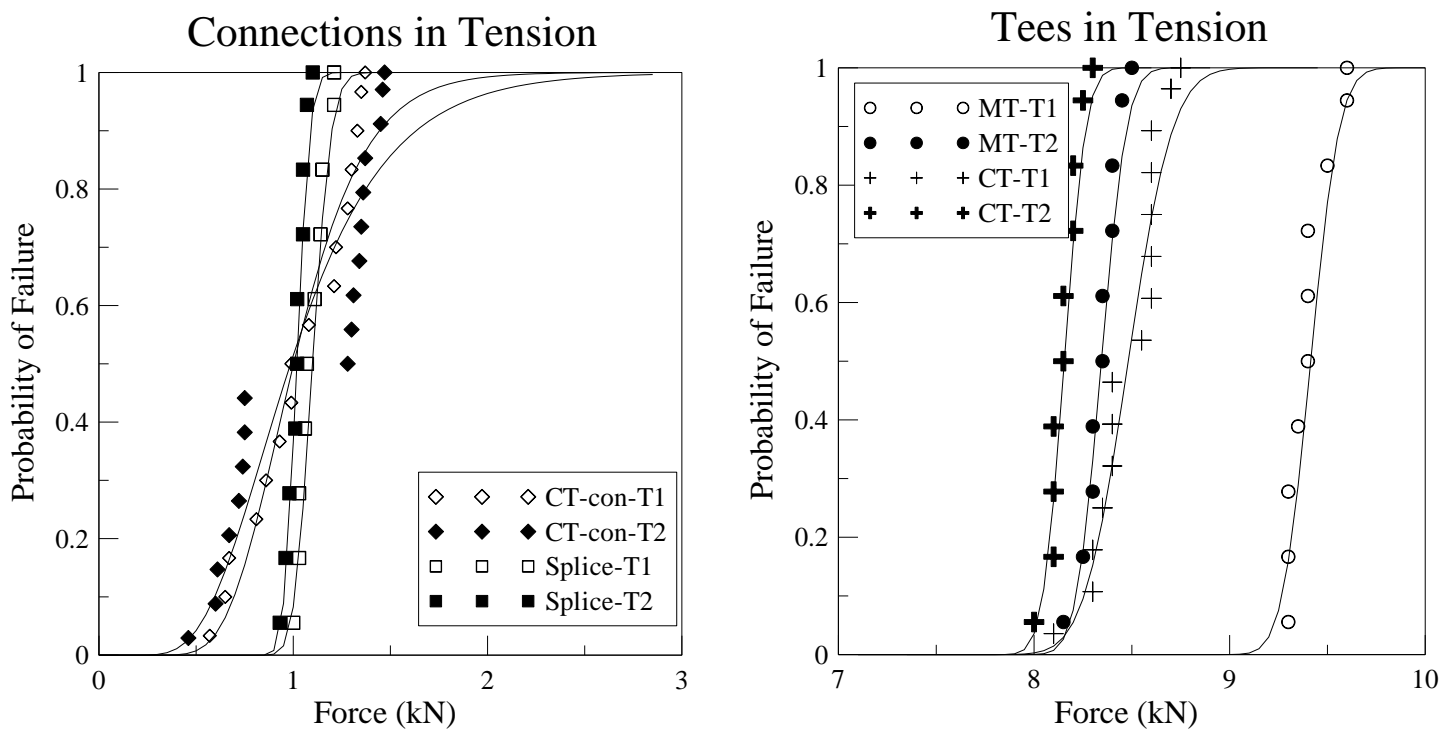

Figure 18: Fragility curves for tension tests.
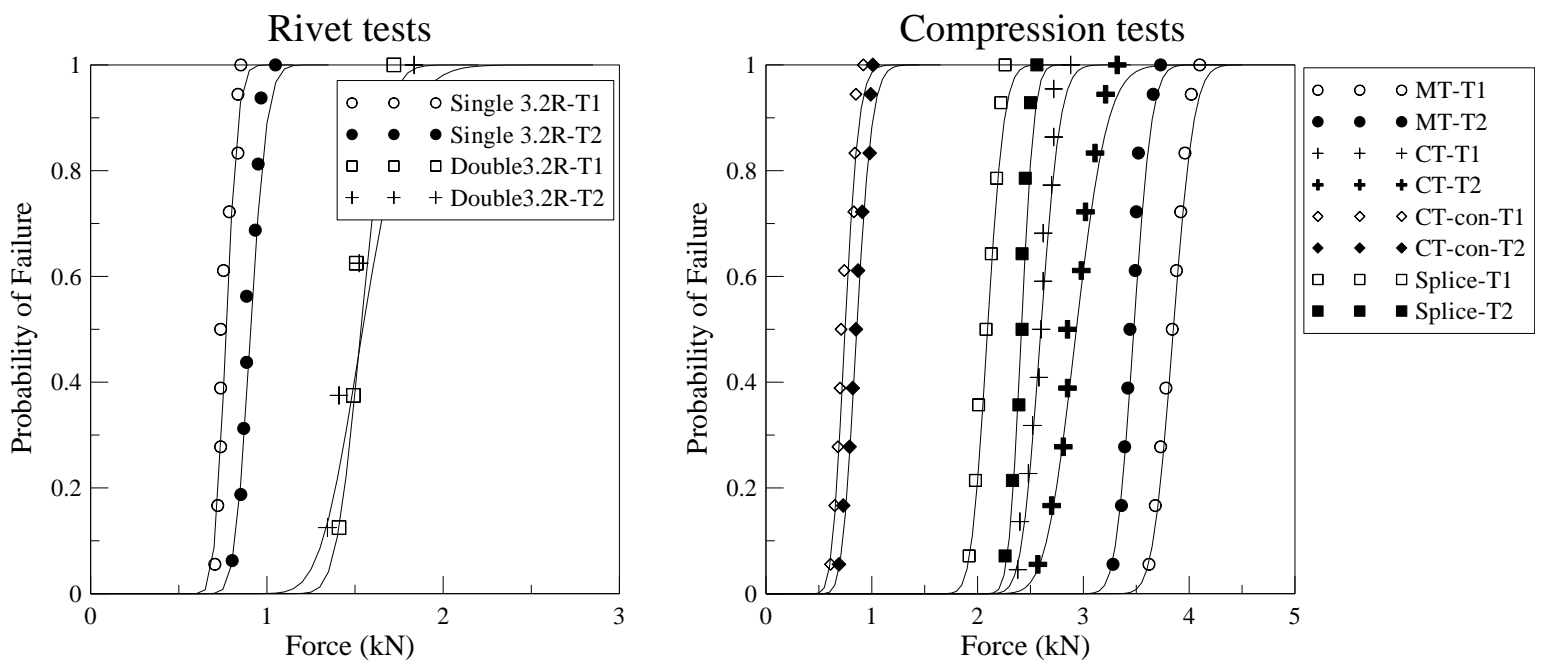

Figure 19: Fragility curves for rivet and compression tests.

Note that the following abbreviations have been used in figures 18 to 20: CT: cross tee, MT: main tee, con: connection, 3.2R: $3.2 \mathrm{~mm}$ Rivet, T1: Type 1 and T2: Type 2.

The general trend in all tests as per Figures 18 and 19 showed that, both under compression and tension, connections failed before the members, making connections the weakest link in the overall capacity chain. In the case of cross tee connections and main tee splices, failure occurred due to the breakage of little fasteners in the joint and in few cases the rivets connecting the joint clip to the member. This means although the tee section performance was satisfactory according to code requirements, the overall system was exposed to failure at demands much lower than the members' capacity due to the weak performance of the connections.

Based on the values of median and standard deviation presented in Table 2 and fragility curves derived in this section, the capacities of components tested can be compared. It can then be concluded that single rivet connections, cross tee connections under compression, main tee splices under tension, cross tee connections under tension and double rivet connections were the more critical components of the system and may dictate the overall capacity of the ceiling system.

\section{Fragility Curves for Ceiling System}

Currently, most residential and commercial suspended ceilings in New Zealand are categorised under a serviceability limit state and are therefore designed for a low level of demand. However, the extensive damage suffered by suspended ceilings in recent New Zealand earthquakes [3,29] proves the need for reconsideration in the assignment of limit state and risk factor applied in the design of these non-structural elements.

For designing a ceiling, knowing the weight of the ceiling chosen, the horizontal design action can be calculated. This horizontal action is a factor of i) ceiling total weight $\left(\mathrm{W}_{\mathrm{p}}\right)$, ii) horizontal acceleration coefficient $\left(\mathrm{C}_{\mathrm{p}}\left(\mathrm{T}_{\mathrm{p}}\right)\right)$ described in previous sections of this paper, iii) the part horizontal response factor $\left(\mathrm{C}_{\mathrm{ph}}\right)$ which is equal to 1 for ceilings with a ductility of 1 and iv) part risk factor $\left(R_{p}\right)$ which is based on the importance of the building or room the ceiling is installed in, and can vary between 0.9 and 2 .

The dimensions of the appropriate ceiling for each case are determined based on the allowable capacity of the grid system. According to ASTM E580 [11], "only heavy-duty main tees can be used in areas of seismic category D-F i.e. high seismic risk. The main tees and cross tees of the ceiling system and 
their splices, intersection connectors, and expansion devices shall be designed and constructed to carry a mean ultimate test load of not less than $180 \mathrm{lb}$ [80 kgf] in compression and in tension. The connectors at splices and intersections shall be the mechanical interlocking type." This is almost in agreement with the test results presented in Table 2 as the weakest components of the ceiling system -cross tee to main tee connections- have a median capacity of $0.73 \mathrm{kN}$ and $0.86 \mathrm{kN}$ for the two manufacturers.

In this section, fragility of a perimeter-fixed ceiling with ceiling grid acceleration as the intensity measure is developed using the components fragility curves from the previous section and considering that the ceiling system is as strong as its weakest component. The analysis presented herein uses perimeter fixed ceilings without any vertical struts and/or diagonal bracing, which are very common in NZ as bracing is not required for ceilings of small to moderate size. Also, the fragility analysis presented in the paper does not account for vertical acceleration effect and falling of tiles due to distortion (before mechanical failure) of ceiling grid members and connections.

The ceiling example was assumed to be located in an area of relatively high seismicity risk (seismic zone factor $\mathrm{Z}=0.3$ ) and on various levels of a 5 storey commercial building having an importance level of 2 . According to proprietary guideline requirements $[10,28]$, individual ceiling tiles must not weigh more than $10 \mathrm{~kg}$. The seismic weight used in the design of the ceiling must also include the grid mass $\left(1 \mathrm{~kg} / \mathrm{m}^{2}\right)$ and a minimum service load of $3 \mathrm{~kg} / \mathrm{m}^{2}$. Assuming the size of tiles as $1200 \mathrm{~mm} \times 600 \mathrm{~mm}$ and each weighing $10 \mathrm{~kg}$, in the worst case the seismic mass of the ceiling will be:

$\left(10 \mathrm{~kg} / 0.72 \mathrm{~m}^{2}\right)+3 \mathrm{~kg} / \mathrm{m}^{2}+1 \mathrm{~kg} / \mathrm{m}^{2}=17.9 \mathrm{~kg} / \mathrm{m}^{2}$

The total seismic mass of the ceiling for the design was therefore assumed as $17.9 \mathrm{~kg} / \mathrm{m}^{2}$. This mass was used to design ceilings based on the recommendations of ceiling manufacturers $[10,28]$. One example of the designed ceilings on the forth level was $4.1 \mathrm{~m} \times 7.1 \mathrm{~m}$ with main tees in the shorter direction and single $3.2 \mathrm{~mm}$ Aluminium rivets connecting the tees to wall angles on two adjacent sides. Fragility curves were derived based on the three most vulnerable components: single rivets, cross tee connections in compression and main tee splices in tension. For any given grid acceleration, the seismic force on the longer dimension of the ceiling is calculated using the assumed seismic mass and Equation 1. The probability of failure of the weakest component in that direction -e.g. cross tee in compression- is derived for the associated seismic force from the fragility curve in Figure 19. This probability of failure will be assigned to the grid acceleration considered. After considering all weak components, an envelope curve is drawn on the furthest left end of the group of fragility curves. This envelope represents the system capacity of the perimeter-fixed ceiling being considered (Figure 20).

The horizontal design coefficient on level four was determined for both SLS with a 25 year return period and an ULS event with a 500 year return period (structural design level). The probability of failure of the designed ceiling was evaluated for both limit states (Figure 20). As it can be observed in the fragility curves, the designed system on level 4 performs satisfactorily when subject to a serviceability level acceleration (probability of failure $\sim 5 \%$ ). However when compared with the ultimate level excitation demand, the probability of failure is $100 \%$, i.e. failure is inevitable.

\section{Effect of Ceiling Area and Tile Weight}

Based on Equation (1), the force induced in a grid member increases as the grid expands in length. Also, heavier tiles lead to greater demand on the ceiling grid. The effect of these factors is shown in fragility curves in this section.

For investigating the effect of area, three ceilings were designed with the same seismic mass of $17.9 \mathrm{~kg} / \mathrm{m}^{2}$ but having three different seismic demands, basically due to the difference in height of the floor supporting the designed ceiling. Ceilings consequently vary in size but all are within the $93 \mathrm{~m}^{2}$ area limit of perimeter-fixed ceiling without seismic bracing (Figure 21). The design of the ceilings is carried out according to the guidelines provided by the ceiling manufacturer. Details of the seismic demand also calculated based on NZS 1170.5:2004 [17] are provided below. These seismic demands showed a close proximity to the demand calculated based on the recommendations of the manufacturer's guideline.

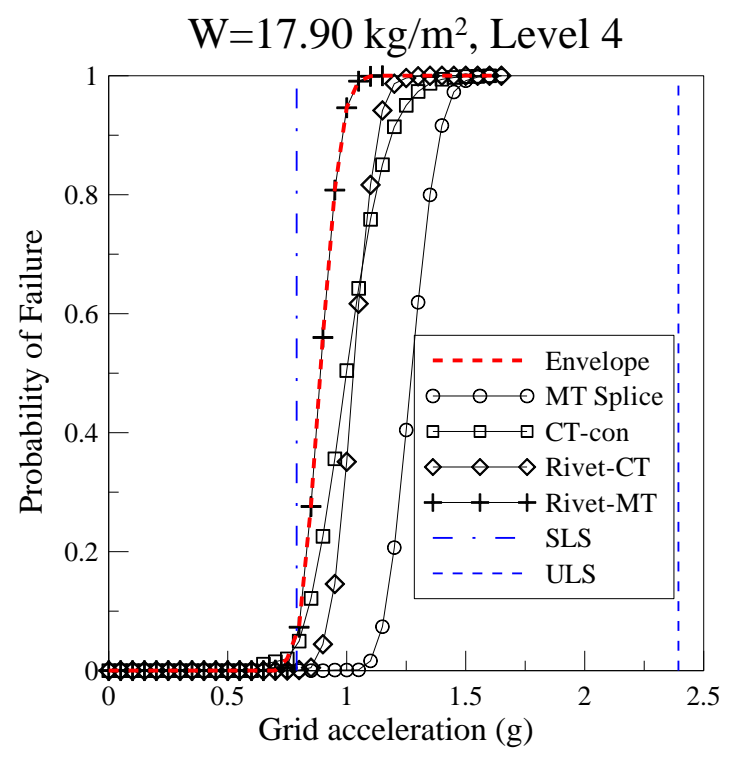

Figure 20: Fragility curves for the designed ceiling on Level four.

Notations: CT-con: Cross tee connection, MT: Main tee, con:, Rivet$C T$ : Rivet on cross tee, Rivet-MT: Rivet on main tee SLS: Serviceability limit state, ULS: Ultimate limit state

Seismic demand on ceiling type A, located in Christchurch (Seismic zone factor, $\mathrm{Z}=0.3 \&$ Near-fault factor, N(T,D) $=1$ ) on soil type $\mathrm{C}$ (Spectral shape factor at zero second period, $\left.C_{h}(0)=1.33\right)$ ), for SLS (Return period factor, $R=0.33$, on the second floor (Floor height coefficient, $\mathrm{C}_{\mathrm{Hi}}=2$ ):

$$
\begin{aligned}
& C(0)=C_{h}(0) \cdot Z \cdot R \cdot N(T, D)=1.33 \times 0.3 \times 0.33 \times 1=0.132 \\
& C_{p}\left(T_{p}\right)=C(0) \cdot C_{H i} \cdot C_{i}\left(T_{p}\right)=0.132 \times 2 \times 2=0.527 \\
& F_{p h}=C_{p}\left(T_{p}\right) \cdot C_{p h} \cdot R_{p} \cdot W_{p}=0.527 \times 1 \times 1 \times 17.9= \\
& F_{p h}=9.43 \mathrm{~kg} / \mathrm{m}^{2}
\end{aligned}
$$

where $C_{p}\left(T_{p}\right)$ is the horizontal acceleration coefficient, $C(0)$ is the elastic site spectra at zero second period, $\mathrm{C}_{\mathrm{i}}\left(\mathrm{T}_{\mathrm{p}}\right)$ is the part spectral shape coefficient, $\mathrm{W}_{\mathrm{p}}$ is the part seismic weight, $\mathrm{C}_{\mathrm{ph}}$ is part response factor, $R_{p}$ is part risk factor and $F_{p h}$ is the horizontal seismic design action. 

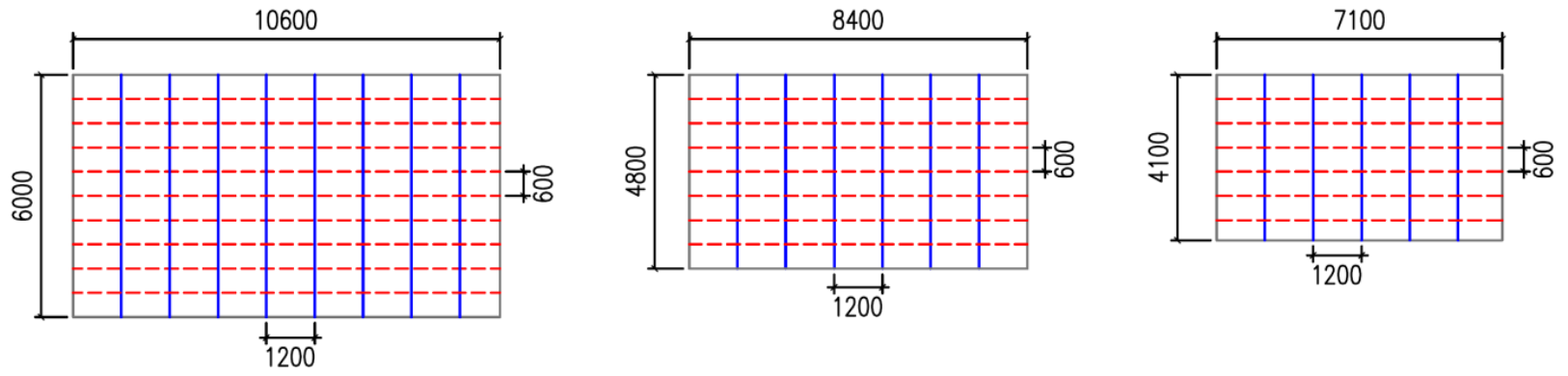

Figure 21: Ceiling schematic, main tees in bold and cross tees in dashed line.

Using the demand above and the capacity of ceiling components: Main tee length $=6,000 \mathrm{~mm}$, cross tee length $=$ $10,600 \mathrm{~mm}$.

Seismic demand on ceiling type A with same location and return period properties but on the third floor $\left(\mathrm{C}_{\mathrm{Hi}}=2.5\right)$ :

$$
\begin{aligned}
& F_{p h}=C_{p}\left(T_{p}\right) \cdot C_{p h} \cdot R_{p} \cdot W_{p}=0.658 \times 1 \times 1 \times 17.9= \\
& F_{p h}=11.78 \mathrm{~kg} / \mathrm{m}^{2}
\end{aligned}
$$

Using the demand above and the capacity of ceiling components: Main tee length $=4,800 \mathrm{~mm}$, cross tee length $=$ $8,400 \mathrm{~mm}$.

Seismic demand on ceiling type A with same location and return period properties but on the forth and higher floors $\left(\mathrm{C}_{\mathrm{H}}\right.$ $=3)$ :

$$
\begin{aligned}
& F_{p h}=C_{p}\left(T_{p}\right) \cdot C_{p h} \cdot R_{p} \cdot W_{p}=0.79 \times 1 \times 1 \times 17.9= \\
& F_{p h}=14.14 \mathrm{~kg} / \mathrm{m}^{2}
\end{aligned}
$$

Using the demand above and the capacity of ceiling components: Main tee length $=4,100 \mathrm{~mm}$, cross tee length $=$ $7,100 \mathrm{~mm}$.

Based on the length of the tees and the seismic demand on ceiling components, fragility curves were derived for each of the ceilings shown in Figure 21. The fragility curves shown in Figure 22a are the envelope curve of the most critical components identified through testing, i.e. single $3.2 \mathrm{~mm}$ rivets, cross tee connections in compression and main tee splices in tension.

In order to investigate the effect of ceiling weight, ceilings were then designed assuming three different seismic mass values; Light: $5.5 \mathrm{~kg} / \mathrm{m}^{2}$; Average: $9.5 \mathrm{~kg} / \mathrm{m}^{2}$ compared with the previously mentioned; Heavy: $17.9 \mathrm{~kg} / \mathrm{m}^{2}$ example. These ceilings are all assumed to have the same area of $7.1 \mathrm{~m} \times 4.1$ $\mathrm{m}$ and are located in similar conditions. Figure $22 \mathrm{~b}$ shows the fragility curves associated with these ceilings.

As it can be observed in Figure 22, the demand on a ceiling is proportional to its size and weight. Using lighter tiles can increase the failure acceleration demand as much as 3 times. Ceilings of a relatively small size $\left(29.1 \mathrm{~m}^{2}\right)$ but supporting heavy tiles $\left(17.9 \mathrm{~kg} / \mathrm{m}^{2}\right)$ show $50 \%$ chance of failure at a horizontal grid acceleration of about $0.9 \mathrm{~g}$. The same ceiling with light tiles $\left(5.5 \mathrm{~kg} / \mathrm{m}^{2}\right)$ instead has a median failure probability at $2.9 \mathrm{~g}$.

Table 3 provides the values of horizontal acceleration coefficient $C_{p}\left(T_{p}\right)$ for serviceability and ultimate limit states at different levels in an example building in Christchurch based on the amendments to New Zealand code [17] described in details earlier in this Section. Note that the SLS return period factor has been raised to 0.33 based on the new draft of the aforementioned code.
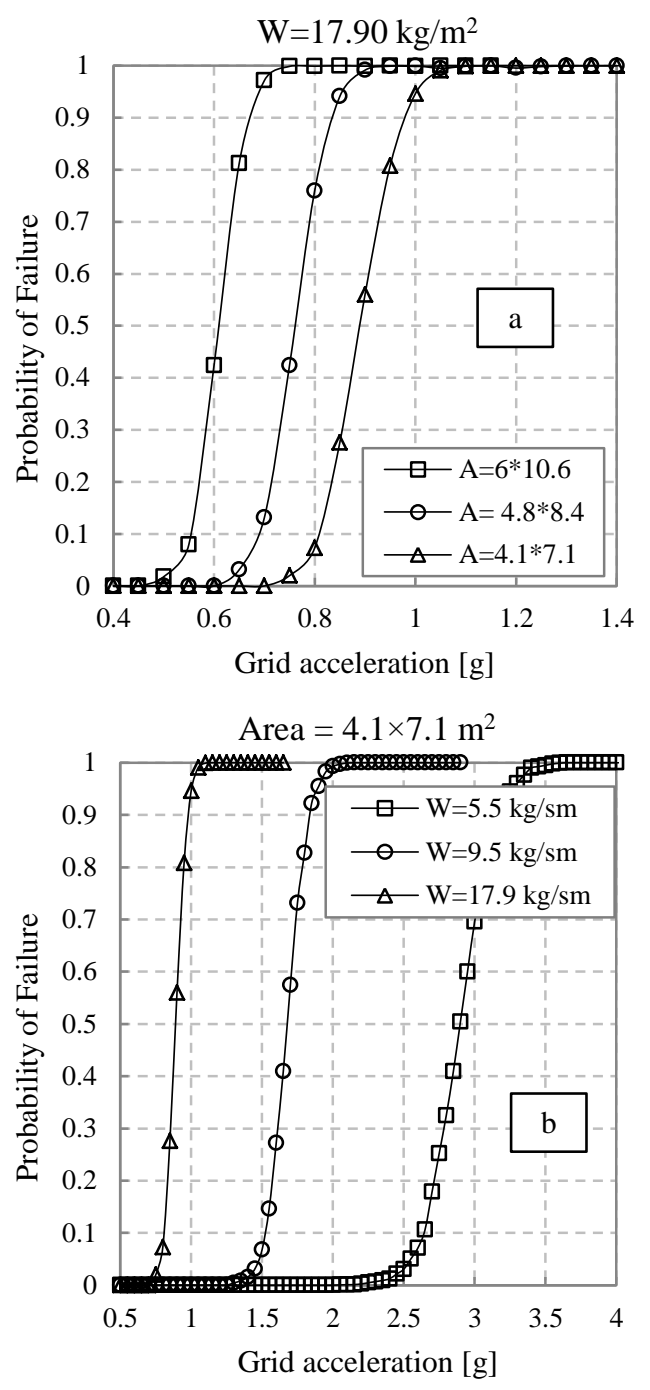

Figure 22: Fragility curves for ceilings with different (a) areas and (b) weights.

The $4.1 \times 7.1 \mathrm{~m}^{2}$ perimeter-fixed ceiling with heavy tiles, if for instance is installed on the second floor of a building in Christchurch on a location with soil type $\mathrm{C}$, will probably sustain some damage in an ultimate limit state seismic event (structural design earthquake). That is because the horizontal acceleration coefficient $\mathrm{C}_{\mathrm{p}} \mathrm{T}_{\mathrm{p}}$ at the second level of the supporting structure is 1.596 which according to Figure $22 \mathrm{~b}$ will have a $100 \%$ probability of failure. Using average weight tiles $\left(9.5 \mathrm{~kg} / \mathrm{m}^{2}\right)$ on the same ceiling area should decrease the probability of failure to about $25 \%$ and the ceiling with very light tiles is expected to not sustain any damage. 
Table 3: Horizontal acceleration coefficient.

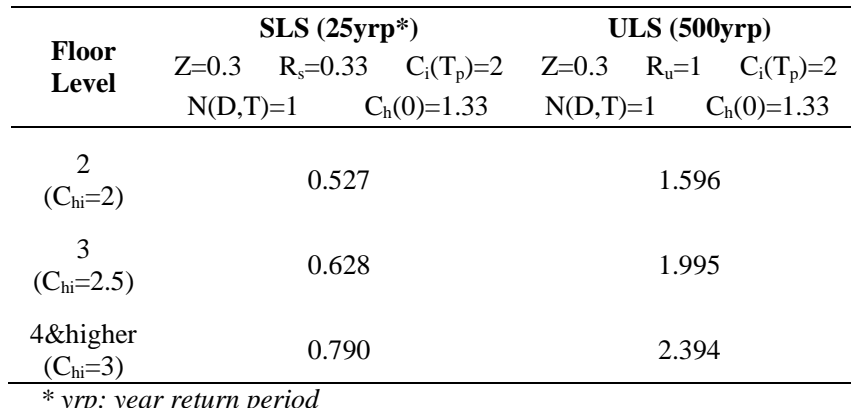

When subject to serviceability level demand, all three ceilings with very light, average and heavy tiles are expected to perform satisfactorily. Only in ceilings with heavy tiles on the fourth or higher floor levels a $5 \%$ probability of failure is observed in fragility curves.

A larger area has similar effect on the overall demand on the perimeter-fixed ceiling. Figure 22a shows the probability of failure in ceilings with heavy tiles and different areas. All three ceilings undergo $100 \%$ failure when subject to an ultimate limit state level event. With $6 \times 10.6 \mathrm{~m}^{2}$ area on the first or second floors, the ceiling has less than $10 \%$ probability of failure at a serviceability level event. The probability of failure is almost similar for ceilings with areas $4.8 \times 8.4 \mathrm{~m}^{2}$ and $4.1 \times 7.1 \mathrm{~m}^{2}$ designed to be located on the $3^{\text {rd }}$ and $4^{\text {th }}$ floors, respectively.

Considering a variety of ceiling weights and dimensions and using envelope fragility curves, graphs presented in Figures 23 and 24 show the correlation between ceiling size and weight and the peak ceiling grid acceleration. These graphs have been derived based on the component tests presented in this study and apply to perimeter-fixed ceilings of the same properties (refer to the methodology section for size of rivets, cross tees and main tees). The graphs presented in Figure 23 have been created using the median capacity of the weakest element of the load path in a ceiling, while graphs in Figure 24 use the $5^{\text {th }}$ and $16^{\text {th }}$ percentile failure values. In each figure two sets of graphs have been presented; for main tees and cross tees. This is due to the difference in grid spacing. Main tees are installed at $1200 \mathrm{~mm}$ spacing and cross tees at $600 \mathrm{~mm}$ intervals. Therefore, their tributary areas and the inertial force carried are different. According to Figure 23, for instance, if the

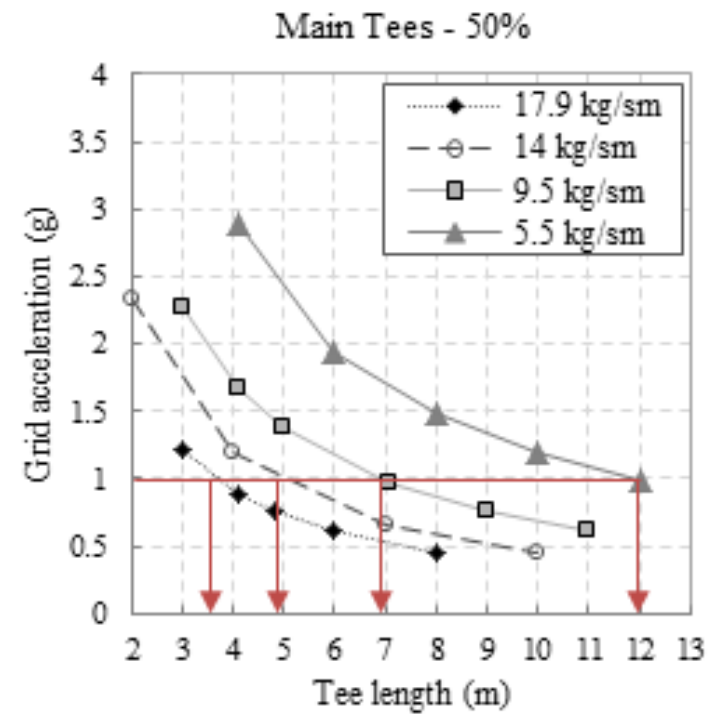

ceiling acceleration at the desired level of structure is $1 \mathrm{~g}$, main tees can be between $3.6 \mathrm{~m}$ to $12 \mathrm{~m}$ based on the weight of the ceiling. Cross tees similarly can expand across a length of 7.1 $\mathrm{m}$ to about $12.2 \mathrm{~m}$ or more.

Graphs and fragility curves shown in this study emphasise the importance of grid length and weight of the ceiling tiles or any other devices supported by the suspension system in finalising the capacity of the perimeter-fixed ceiling system. Therefore, the limit of $93 \mathrm{~m}^{2}$ area for the requirement of back bracing seems insufficient. A ceiling may be perfectly within this area limit but the length of the grid members may exceed the allowable limit. Similarly, a combination of small length but heavy tiles may lead to large demands which are beyond the system's capacity. It seems more advisable to set the requirements of seismic bracing based on the capacity of components and therefore, the allowable combination of grid length and weight rather than area alone.

It is worthwhile to mention that the above observations are merely for the purpose of study. Ceilings currently designed based on the manufacturers' guidelines and New Zealand codes are proportioned in size and weight such that a serviceability level event will not induce damage. According to current practice in New Zealand as reported by manufacturers [13, 28], when ceilings are at risk of high seismic demand or covering large areas of high financial or vital importance, bracing to the above structure is mostly applied as the seismic solution.

\section{Comparing the Proposed Analytical Method with Existing Experimental Data}

In order to evaluate the validity of the proposed simple method of estimating ceiling fragility described in previous sections, comparisons have been made with experimental results from Badillo-Almaraz et al. [33] and Ryu et al. [37]. Both of these experiments were carried out on a similar grid system to what has been tested in this paper. Due to limits of the available experimental data, the following conditions need to be considered in this comparison:

(i) Ceilings in Badillo-Almaraz et al. [33] were fixed on two sides via aluminium rivets. On the other hand, the ceilings tested by Ryu et al. [37] used seismic clips which have slightly less capacity compared to rivets [28].

(ii) The ceiling tested by Badillo-Almaraz et al. [33] was also back braced to the frame roof which makes it stiffer

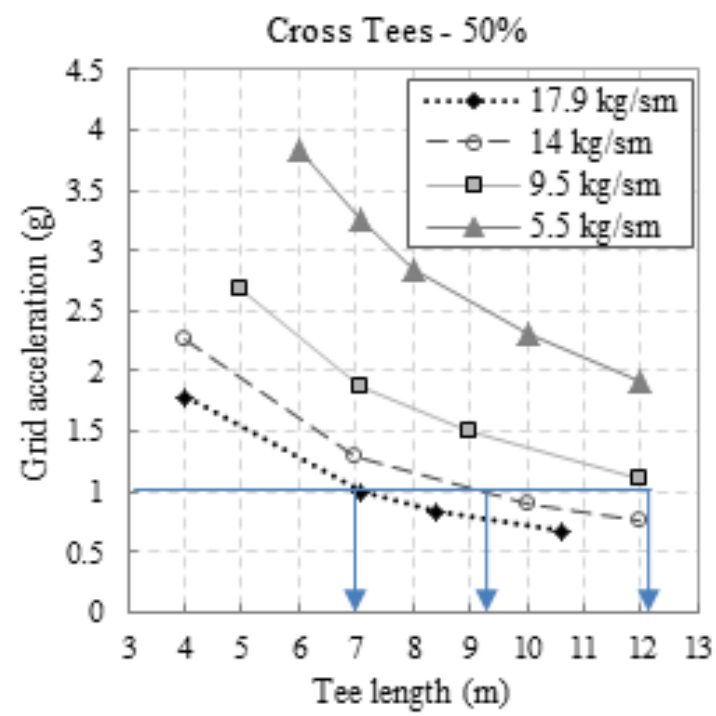

Figure 23: Correlations among grid length, ceiling weight and allowable acceleration using median probability of failure. 

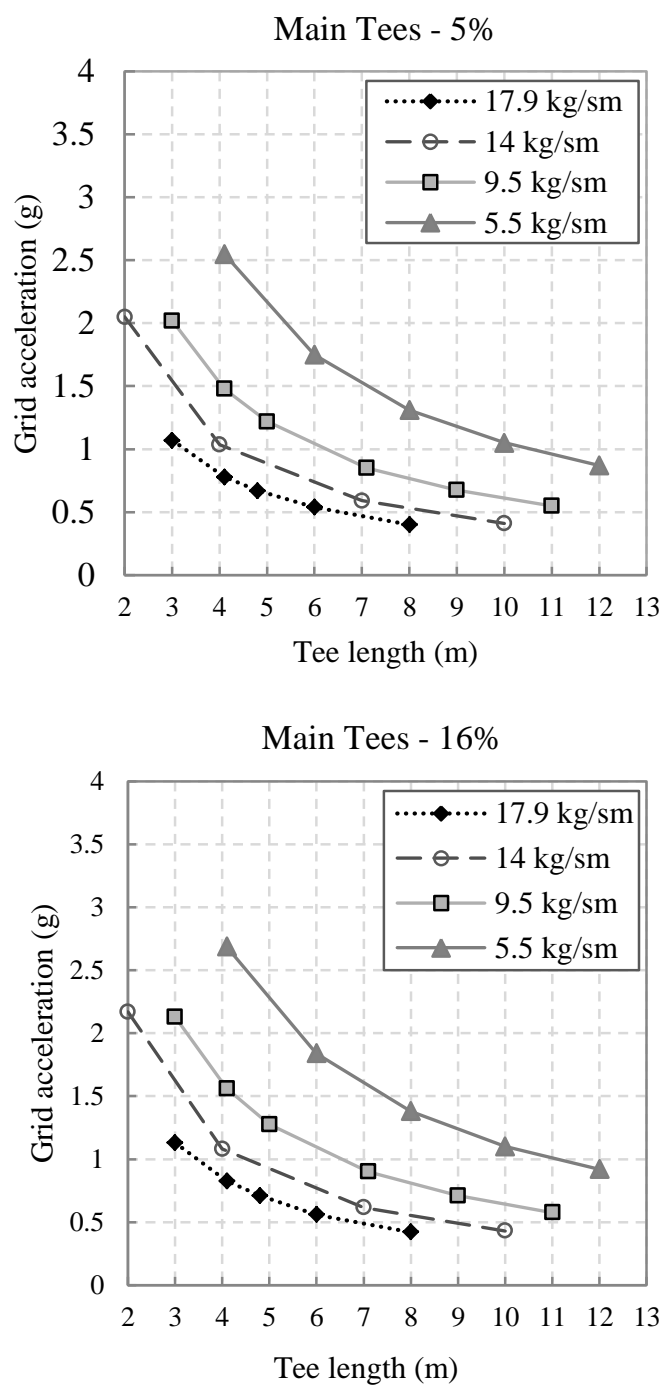

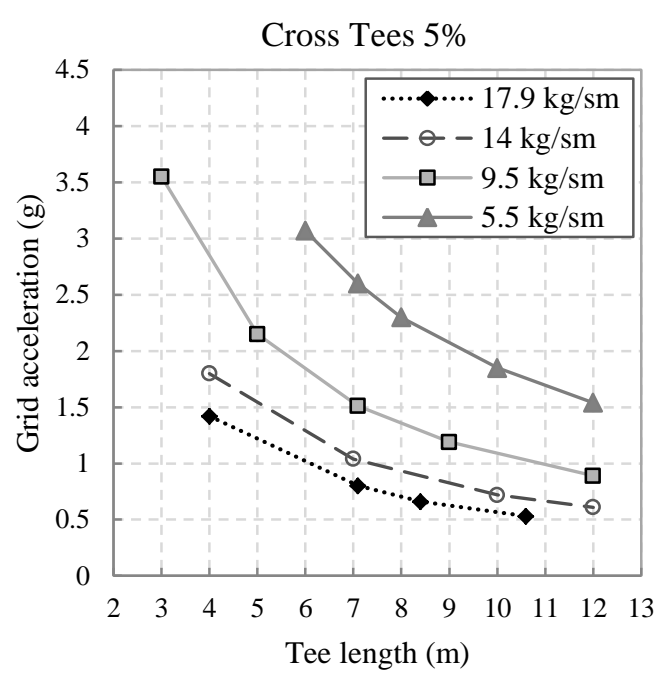

Cross Tees $-16 \%$

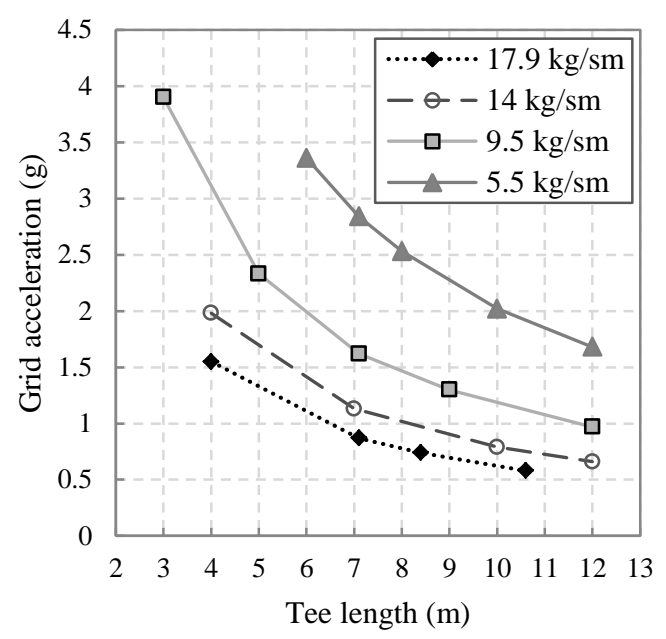

Figure 24: Correlations among grid length, ceiling weight and allowable acceleration using $5 \%$ and $16 \%$ probability of failure.

compared to the perimeter-fixed ceiling used for this proposed analytical method.

(iii)Although Ryu et al. [37] report the recorded peak ceiling grid accelerations (PCGAs) associated with the commencement of two damage states considered, BadilloAlmaraz et al. [33] provide fragility curves with PFA as the intensity measure. The proposed analytical method is based on PCGA. To overcome this discrepancy, a simplifying assumption has been made; the values of PFA are amplified by a factor of 3 to obtain the PCGA. This amplification factor is based on the observations made by Ryu et al. [37] and Pourali et al. [40].

(iv) The fragility curves available in Badillo-Almaraz et al. [33] are for ceilings with undersized tiles. Use of undersized tiles decreases the resilience of the ceiling. However, the threshold PFA for grid failure damage state was the same for undersized and normal-sized ceiling specimen.

(v) In the proposed method the capacity of the ceiling is estimated only under horizontal excitation as opposed to 3D in Ryu et al. [37] and 2D in Badillo-Almaraz et al. [33]. The effect of bidirectional and vertical motions has not been considered.
Using the tile weight and dimensions of the ceilings tested by Ryu et al. [37] and Badillo-Almaraz et al. [33] (Figure 25) and components fragility curves in earlier sections, ceiling fragility curves are derived based on the simplified method presented in this paper. Values of acceleration at the onset of repairable damage and collapse based on Ryu et al. [37] are shown in Table 4.

In Table 4 assemblies \#12 and \#14 have only been included for comparison with \#11 and \#13. These assemblies were similar to \#11 and \#13 respectively with the exception of back bracing added. The perimeter connections were also rivets instead of seismic clips.

Figure 26a shows the experimental fragility curves obtained from Badillo-Almaraz et al. [33] tests plotted after converting the peak floor acceleration (PFA) to ceiling grid acceleration (PCGA). The experimental fragility curves corresponding to two different damage states monitored in the tests are compared with an analytical fragility curve derived for a perimeter-fixed ceiling of the same size and weight. As can be noticed in the figure, the analytical fragility curve is in better agreement with the experimental grid failure fragility. This is expected as the analytical procedure considers the failure of any grid member (and connections) as the damage state. 


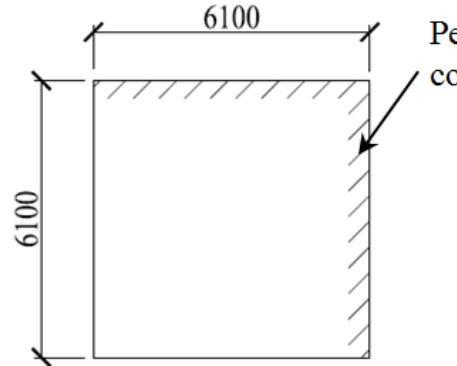

Ryu \#11

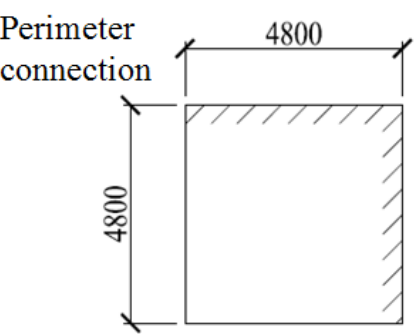

Ryu \#13

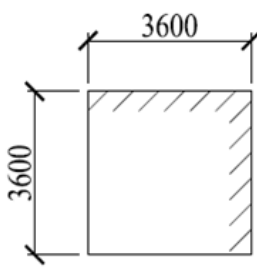

Ryu \#15

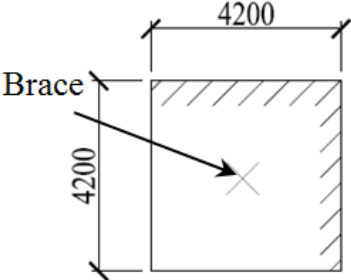

Badillo

Figure 25: Specimens used in comparison [33, 37].

Table 4: Acceleration levels at the onset of repairable damage and collapse in tests [37].

\begin{tabular}{cccccc}
\hline \multirow{2}{*}{$\begin{array}{c}\text { Ceiling } \\
\text { Dimension }\end{array}$} & $\begin{array}{c}\text { Damage } \\
\text { State }\end{array}$ & \multicolumn{2}{c}{$\begin{array}{c}\text { Onset of Repairable } \\
\text { Damage* }\end{array}$} & \multicolumn{2}{c}{ Onset of Collapse** } \\
\cline { 2 - 3 } & Assembly & PFA $(\mathbf{g})$ & PCGA $^{* * *}(\mathbf{g})$ & PFA $(\mathbf{g})$ & PCGA*** $(\mathbf{g})$ \\
\hline $6 \mathrm{~m} \times 6 \mathrm{~m}$ & $\# 11$ & - & - & 1.54 & 3.48 \\
$6 \mathrm{~m} \times 6 \mathrm{~m}$ & $\# 12$ & 1.76 & 3.57 & 2.02 & 3.75 \\
$4.8 \mathrm{~m} \times 4.8 \mathrm{~m}$ & $\# 13$ & - & - & 1.99 & 3.72 \\
$4.8 \mathrm{~m} \times 4.8 \mathrm{~m}$ & $\# 14$ & 1.65 & 3.22 & 1.95 & 3.57 \\
$3.6 \mathrm{~m} \times 3.6 \mathrm{~m}$ & $\# 15$ & 2.66 & 5.32 & 2.65 & 5.59
\end{tabular}

* Repairable damage: "minor dislocations of tiles or grids in isolated places of the ceiling without losing stability and the support of the rest of the ceiling." This damage may require replacement of several tiles and a few cross tees (Ryu et al. 2013 [37]).

** Collapse: loss of grid and tiles requiring complete replacement of the ceiling. This state is defined as the failure of $10 \%$ of the total number of grids or tiles (Ryu et al. 2013 [37]).

\section{*** PCGA: Peak ceiling grid acceleration}

Analytical vs. Badillo-Almaraz et al. [33]

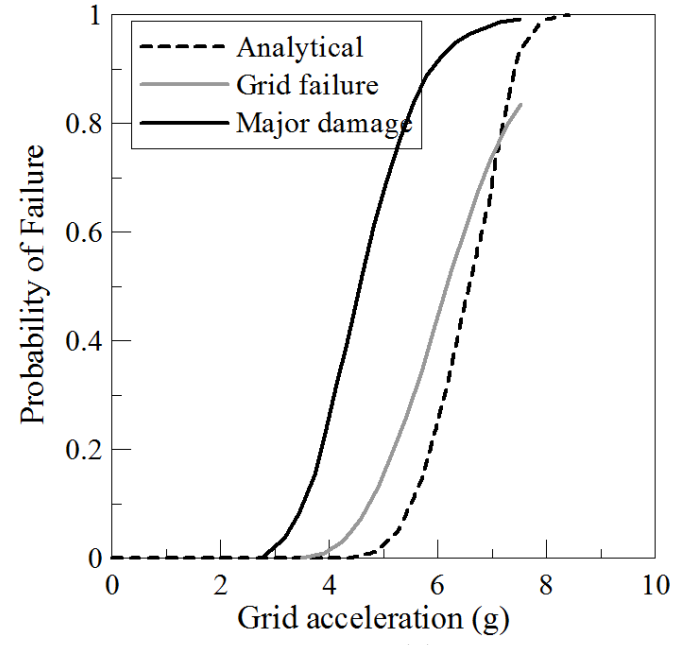

(a)
Analytical vs. Ryu et al. [37]

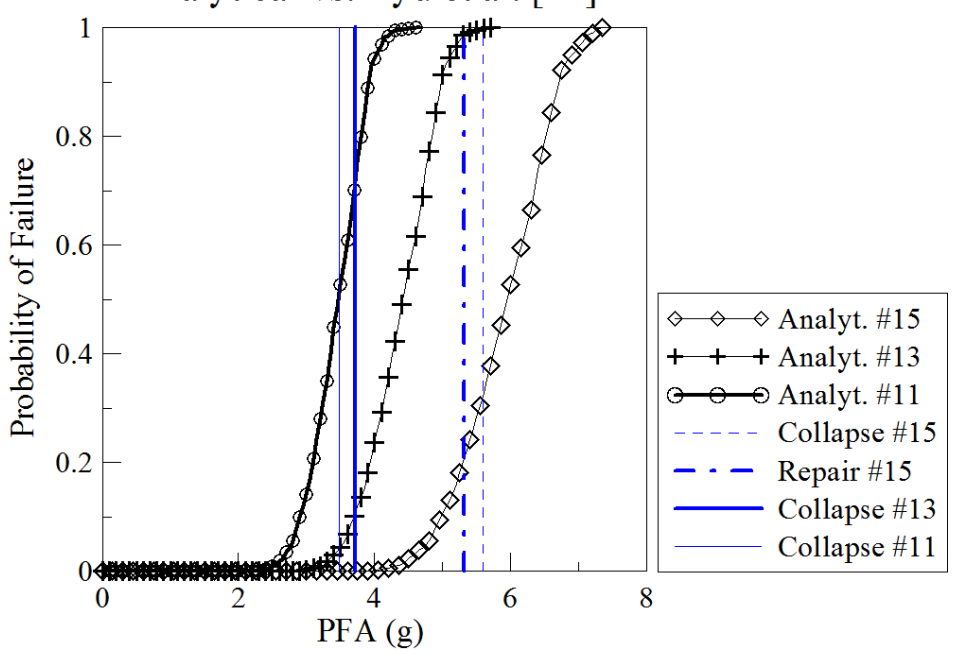

(b)

Figure 26: Comparison between experimental [33, 37] and proposed analytical fragility curves.

Figure 26b shows the proposed analytical fragility curves associated with three test specimens in Ryu et al. [37] along with grid accelerations at the onset of repair or collapse. In all three specimens, the experimentally obtained ceiling grid acceleration capacity lies within the range covered by the analytical fragility curves. In assembly \#11, which is the largest of the three, the peak grid acceleration at the onset of collapse is associated with $50 \%$ probability of failure in the proposed fragility curve. In assembly \#13 the onset of collapse happens at the PCGA corresponding to $10 \%$ failure probability in the analytical fragility curve. In assembly \#15 the PCGA at the onset of repair and collapse are associated with $20 \%$ and $32 \%$ probability of failure, respectively. Considering all the simplifications and assumptions mentioned above, the analytical fragility curve provides a relatively good estimation of the experimental results. Given that failure or damage in suspended ceilings depends on the type of suspension system used, size and weight of the particular ceiling, it is unlikely that relevant experimental reference can be found for the design of each particular ceiling. Therefore this initial estimate can be useful in the preliminary prediction of probable loss in perimeter-fixed ceilings. 


\section{CONCLUSIONS}

A study was conducted on typical suspended ceilings in NZ The following conclusions have been drawn from this study:

1. Standards exist for loading, design and installation of suspended ceilings or related non-structural elements. However, since most ceilings are proprietary systems, reliance is made on the ceiling manufacturers to ensure that these conditions are satisfied.

2. Significant damage has been observed in suspended ceilings in past earthquakes in NZ and overseas. Damage types include: i) dislodging and breaking of the tiles, ii) failure of the ceiling grid members and connections, iii) grid spreading, iv) failure of perimeter tiles, v) perimeter damage due to failure of grids or end fixings in compression to rigid walls or columns, vi) failure caused by insufficient bracing on supporting partition walls and vii) damage to ceiling tiles and grids due to interaction with services.

3. Experimental and analytical results concerning the capacity of typical suspended ceilings in New Zealand were presented. Results from static tests on these ceiling components in the form of component fragility curves show that most critical components of the perimeter-fixed ceiling can be identified as: single rivet connections $(3.2$ $\mathrm{mm}$ ), cross tee connections under compression, main tee splices under tension, cross tee connections under tension and double rivet connections $(3.2 \mathrm{~mm}$ ) (in order of weakness).

4. A simple method has been proposed for the analysis of perimeter-fixed suspended ceilings with peak grid acceleration as the demand and the length of the grid members and the overall seismic mass as parameters limiting the capacity. Using the component fragility curves, the overall fragility of the ceiling system has been estimated based on the principles of a capacity chain and the assumption of linear accumulation of seismic force in ceiling components.

5. Effect of ceiling weight and grid length on the overall capacity of the ceiling has been investigated through comparison of designed example ceilings. Results show that a combination of ceiling weight and grid length needs to be considered for estimating the allowable acceleration applied to the ceiling. The performance of designed ceilings of various sizes and weights has also been compared with serviceability and ultimate limit state demands. The simple method provided in this study can be used for a quick estimation of the allowable length and weight for a typical perimeter-fixed ceiling subject to a given grid acceleration.

6. The analytical fragility curves proposed for the perimeterfixed ceilings in this paper have been compared with relatively similar experimental fragility curves by other researchers. The comparison shows that the proposed method is relatively conservative in estimating the fragility of the system but can be used as an initial estimation of the probability of failure.

This study has proposed fragility functions for perimeter fixed ceiling systems assuming that the forces in different grid members and their connections are directly proportional to the ceiling acceleration and the total force in each direction is uniformly distributed among different grid members acting in that direction. As an extension to this study, the authors are currently assessing the validity of (and deviations from) these assumptions by conducting shaking table tests on different types of ceiling systems including the unbraced perimeterfixed ceilings considered herein. Although detail results will be reported in future publications, the study has so far indicated that the axial force in a grid member can be reliably taken as being proportional to its acceleration but the forces in different grid members in a direction can differ substantially depending on the nature of the perimeter connections.

\section{REFERENCES}

1 Taghavi S and Miranda E (2003). "Response Assessment of Non-structural Building Elements". Report PEER 2003/05, Pacific Earthquake Engineering Research Center, University of California, Berkeley, USA, 96 pp.

2 MacRae GA and Lehman D (2001). "Chapter 4, Buildings", in "The Nisqually Washington Earthquake, February 28, 2001 Preliminary Reconnaissance Report". Co-authored by the Nisqually Earthquake Clearinghouse Group, University of Washington, Seattle. Earthquake Engineering Research Institute, EERI Learning from Earthquakes Project, USA.

3 Dhakal RP (2010). "Damage to Non-Structural Components and Contents in 2010 Darfield Earthquake". Bulletin of the New Zealand Society for Earthquake Engineering, 43(4): 404-411.

4 MacRae GA, Pampanin S, Dhakal R, Palermo A, Baird A and Tasligedik S (2012). "Review of Design and Installation Practices for Non-Structural Components", Report prepared for the Engineering Advisory Group of the Department of Building and Housing by New Zealand Consultants, Industry and Related Experts, NZ, June 2012.

5 Bradley B, Dhakal R, MacRae G and Cubrinovski M (2010). "Prediction of Spatially Distributed Seismic Demands in Specific Structures: Structural Response to Loss Estimation". Earthquake Engineering and Structural Dynamics, 39(6), 591-613.

6 Ferner H, Wemyss M, Baird A, Beer A and Hunter D (2014). "Seismic performance of non-structural elements within buildings". Proceedings of New Zealand Society of Earthquake Engineering (NZSEE) Conference, Auckland, NZ, 21-23 March 2014.

7 Masato Motosakaa and Kazuya Mitsujib (2012). "Building Damage during the 2011 off the Pacific Coast of Tohoku Earthquake". Journal of Soils and Foundations, 52(5): 929-944.

8 Nation http:/www nationmultimedia com/headlines/At-least-20dead-after-8-8-magnitude-tremor-30150675.html.

9 FEMA E74 (2011). "Reducing the Risks of Non-Structural Earthquake Damage - A Practical Guide”. Washington D.C., USA.

10 USG Australia (2012). "Generic Seismic Design for USG DONN Exposed Grid Suspended Ceilings". Auckland, New Zealand.

11 American Society for Testing and Materials International (2011). "E580/E580M-11b 2011.Standard Practice for Installation of Ceiling Suspension Systems for Acoustical Tile and Lay-in Panels in Areas Subject to Earthquake Ground Motions". PA, USA.

12 Australian/New Zealand Standard (2000). "AS/NZS 2785:2000 Suspended ceilings - Design and Installation". Standards New Zealand, Wellington, NZ.

13 USG Australia (2011). "DONN Brand Grid Suspension System”. USG Australia, Auckland, NZ.

14 Rondo (2008). "DUO Two-way Exposed Suspended Ceiling Grid System”. Rondo, Auckland, NZ.

15 American Society for Testing and Materials (2013). "C636/C636M-Standard Practice for Installation of Metal Ceiling Suspension Systems for Acoustical Tile and Lay-in Panels". PA, USA.

16 Dhakal RP and MacRae G (2013). "Ceiling Systems 
Design and Installation Lessons from the Canterbury Earthquakes". Proceedings of 10th International Conference on Urban Earthquake Engineering (10CUEE), Tokyo Institute of Technology, Tokyo, Japan, 1-2 March 2013.

17 New Zealand Standard (2004). "NZS 1170.5:2004, Structural Design Actions Part 5: Earthquake actionsNew Zealand". Standards New Zealand, Wellington, NZ.

18 New Zealand Standard (2009). "NZS 4219:2009, Seismic Performance of Engineering Systems in Buildings". Standard New Zealand, Wellington, NZ.

19 New Zealand Standard (2013). “NZS 4541:2013 Automatic fire sprinkler systems". Standard New Zealand, Wellington, NZ.

20 Ministry of Works (1985). "PW/81/10/1:1985 Guidelines for the Seismic Design of Public Buildings: Appendix D Suspended Ceilings and Associated Fittings and Fixtures". MoW, Wellington, NZ.

21 Australian/New Zealand Standard (2002). "AS/NZS 1170.1:2002 Structural design actions - Part 1: Permanent, Imposed and Other Actions". Standards New Zealand, Wellington, NZ.

22 Australian/New Zealand Standard (1999). "AS/NZS 1530.3:1999 Methods for Fire Test on Building Materials, Components and Structures - Simultaneous Determination of Ignitability, Flame Propagation, Heat Release and Smoke Release”. Standards New Zealand, Wellington, NZ.

23 Australian Standard (1991), “AS 2946:1991 - Suspended Ceilings, Recessed Luminaires and Air Diffusers Interface Requirements for Physical Compatibility". Standards Australia, Sydney, Australia.

24 American Society of Civil Engineers (1994). "ASCE/SEI 7-10. Minimum Design Loads for Buildings and Other Structures, Vol. 7, Chapter 13: Seismic Design Requirements for Non-Structural Components". American Society of Civil Engineers, USA.

25 American Society for Testing and Materials (2013). "C635/C635M- Standard Specification for the Manufacture, Performance, and Testing of Metal Suspension Systems for Acoustical Tile and Lay-in Panel Ceilings". PA, USA.

26 American Society for Testing and Materials International (2011). "E1414-11 - Standard Test Method for Airborne Sound Attenuation Between Rooms Sharing a Common Ceiling Plenum (Two room method)". PA, USA.

27 Ceilings and Interior Systems Construction Association CISCA (2004). "Guidelines for Seismic Restraint for Direct Hung Suspended Ceiling Assemblies, Seismic Zones 3-4". Ceiling and Interior Systems Construction Association, Illinois, USA.

28 Armstrong (2013). "Seismic Design Guide New Zealand Version, Suspended Ceiling Systems". Armstrong, Auckland, New Zealand.

29 Dhakal RP, MacRae GA and Hogg K (2011). "Performance of Ceilings in the February 2011
Christchurch Earthquake". Bulletin of the New Zealand Society for Earthquake Engineering, 44(4): 379-389.

30 Stuff (2014). http://www.stuff.co.nz/dominionpost/business/commercial-property/9209910/Long-waitfor-BNZ-workers

31 ANCO Engineers Inc. (1983). "Seismic Hazard Assessment of Non-Structural Ceiling Components: Phase I'. Report No. 1249.12, Grant 8114155, National Science Foundation, Culver City, California, USA.

32 Rihal SS and Granneman G (1984). "Experimental Investigation of the Dynamic Behavior of Building Partitions and Suspended Ceilings during Earthquakes". Report No. ARCE R-84-1, California Polytechnic State University, San Luis Obispo, California, USA.

33 Badillo-Almaraz H, Whittaker AS and Reinhorn AM (2007). "Seismic Fragility of Suspended Ceiling Systems". Earthquake Spectra, 23(1): 21-40.

34 Gilani AS, Reinhorn AM, Glasgow B, Lavan O and Miyamoto HK (2010). "Earthquake Simulator Testing and Seismic Evaluation of Suspended Ceilings". Journal of Architectural Engineering, 16(2): 63-73.

35 Gilani AS, Takhirov Sh And Tedesco L (2012). "Seismic Evaluation Procedure for Suspended Ceilings and Components, New Experimental Approach". Proceedings of the 15th World Conference on Earthquake Engineering, Lisbon, Portugal, 20-24 September 2012.

36 Glasgow B, Gilani AS and Miyamoto HK (2010). "Resilient Suspended Ceilings for Sustainable Design of Buildings". Proceedings of Structures Congress, Orlando, Florida, USA, 12-15 May 2010.

37 Ryu KP, Reinhorn AM and Filiatrault A (2013). "Capacity Evaluation of Suspended Ceiling Systems". Technical Report MCEER-13-XXXX, Buffalo, NY, USA.

38 Paganotti G (2010). "Behaviour of Suspended Ceiling System during Seismic Events: Development of Fragility Curves". Masters Thesis, Politecnico Di Milano, Italy.

39 Paganotti G, MacRae GA and Dhakal RP (2011). "Development of Typical NZ ceiling System Seismic Fragilities". Proceedings of the Ninth Pacific Conference on Earthquake Engineering, Building an EarthquakeResilient Society, Auckland, NZ, 14-16 April 2011.

40 Pourali A, Dhakal RP, MacRae GA and Tasligedik AS (2015). "Shake Table Tests of Perimeter-Fixed Type Suspended Ceilings". Proceedings of NZ Society for Earthquake Engineering NZSEE Conference, Rotorua, NZ, 10-12 April 2015.

41 Singh J, MacRae GA, Dhakal RP and Pampanin S (2011). "Building Seismic Ceiling Fragility using Spectral Acceleration". Proceedings of the Ninth Pacific Conference on Earthquake Engineering: Building an Earthquake-Resilient Society, Auckland, NZ, 14-16 April 2011. 